In press at Cognition. This file is a pre-print and may contain errors or omissions not present in the final published version.

\title{
Linguistic Conventionality and the Role of Epistemic Reasoning in Children's Mutual Exclusivity Inferences
}

\author{
Mahesh Srinivasan, ${ }^{1}$ Ruthe Foushee, ${ }^{1}$ Andrew Bartnof, ${ }^{1} \&$ David Barner ${ }^{2}$ \\ ${ }^{1}$ University of California, Berkeley \\ ${ }^{2}$ University of California, San Diego
}

Please address correspondence to:

Mahesh Srinivasan

Department of Psychology

University of California, Berkeley

Berkeley, CA 94720-1650

Phone: 650-823-9488

Email: srinivasan@berkeley.edu 


\begin{abstract}
To interpret an interlocutor's use of a novel word (e.g., "give me the papaya"), children typically exclude referents that they already have labels for (like an "apple"), and expect the word to refer to something they do not have a label for (like the papaya). The goal of the present studies was to test whether such mutual exclusivity inferences require children to reason about the words their interlocutors know and could have chosen to say: e.g., If she had wanted the "apple" she would have asked for it (since she knows the word "apple"), so she must want the papaya. Across four studies, we document that both children and adults will make mutual exclusivity inferences even when they believe that their interlocutor does not share their knowledge of relevant, alternative words, suggesting that such inferences do not require reasoning about an interlocutor's epistemic states. Instead, our findings suggest that children's own knowledge of an object's label, together with their belief that this is the conventional label for the object in their language, and that this convention applies to their interlocutor, is sufficient to support their mutual exclusivity inferences. Additionally, and contrary to the claims of previous studies that have used mutual exclusivity as a proxy for children's beliefs that others share their knowledge, we found that children - especially those with stronger theory of mind ability — are quite conservative about attributing their knowledge of object labels to others. Together, our findings hold implications for theories of word learning, and for how children learn about the scope of shared conventional knowledge.
\end{abstract}

Keywords: mutual exclusivity; epistemic reasoning; word learning; pragmatics; theory of mind; conventions 
Mutual Exclusivity and Conventionality

\section{Linguistic Conventionality and the Role of Epistemic Reasoning in Children's Mutual Exclusivity Inferences}

Children routinely make inferences about the meanings of new words. For example, in a context including a familiar object, like an apple, and a novel one, like a papaya, a child who hears "Can you give me the papaya?" will typically exclude the referent for which they already have a label (e.g., "apple"), and infer that the new word refers to the novel item (e.g., the papaya), a phenomenon known as a "mutual exclusivity inference" (Markman \& Wachtel, 1988). Although such inferences have been documented in children as young as 12 months (Diesendruck \& Markson, 2001; Golinkoff, Hirsh-Pasek, Bailey, \& Wenger, 1992; Graham, Poulin-Dubois, \& Baker, 1998; Halberda, 2006; Markman, Wasow, \& Hansen, 2003; Merriman \& Bowman, 1989; Scofield \& Behrend, 2007; Xu, Cote, \& Baker, 2005), there has been significant debate about their cognitive basis. Inspired by the theories of Paul Grice (e.g., Grice, 1975), some have argued that mutual exclusivity requires children to reason epistemically about words that their interlocutors know (“epistemic accounts;” Bloom, 2000; Diesendruck \& Markson, 2001). For example, a child who believes that her father knows the word "apple" could reason that it would be uncooperative for him to request an apple by asking for a "papaya," leading her to infer that "papaya" likely refers to the papaya. By other accounts, however, children's mutual exclusivity inferences do not require reasoning about epistemic states, but are instead supported by children's own knowledge of words ("non-epistemic accounts;" Markman, 1990, 1991; Markman \& Wachtel, 1988; see also Golinkoff et al., 1992; Merriman \& Bowman, 1989). For example, if the child believes that apples are called "apples," she could reason that they can't also be called "papayas," due to her belief that each object will have a single label in her language; thus, "papaya" must refer to the papaya. In the present studies, we examine the 
role of epistemic reasoning in mutual exclusivity inferences. In the process, we also explore how children infer whether the words that they know are likely to be known by others.

According to epistemic accounts, children should only make mutual exclusivity inferences if they believe that their interlocutor shares their knowledge of relevant, alternative words. Consistent with this prediction, recent work suggests that children make mutual exclusivity inferences only under conditions in which it would be reasonable - from an adult perspective - to attribute shared knowledge to their interlocutors (Diesendruck \& Markson, 2001; Diesendruck, 2005; Diesendruck, Carmel, \& Markson, 2010). In addition to lending putative support to epistemic accounts of word learning, these studies have provided a foundation for an emerging literature on children's understanding of what kinds of cultural knowledge are likely to be shared with others in their community (Diesendruck, 2012; Kalish \& Sabbagh, 2007; Rakoczy \& Schmidt, 2013; Sabbagh \& Henderson, 2007).

For example, in a foundational set of studies, Diesendruck and Markson (2001) argued that children expect familiar object labels to be known by other competent speakers of their language — supporting epistemically-mediated mutual exclusivity inferences about novel object labels — but that they do not hold such expectations about idiosyncratic facts associated with an object. In one experiment, 3-year-olds were taught a new noun ("This is a dax") for one of two novel objects while a puppet named Percy was either present or in his house from where he could not hear anything. When Percy later asked for an object using a second novel noun ("Can you give me the bem?"), children chose the previously-unreferenced object reliably more often than chance - and thus made mutual exclusivity inferences - even when Percy had been absent during the teaching of the first noun. In contrast, in another experiment in which children had been taught an idiosyncratic fact for one of the two novel objects ("I got this for Christmas"), 
and Percy then asked for an object using a second, distinct fact ("Can you give me the one from Mexico?"), children only reliably selected the previously-unreferenced object when Percy had been present throughout the trial, and not when he had previously been absent.

From these findings, Diesendruck and Markson (2001) argued for an epistemic account in which mutual exclusivity inferences arise only when children can assume that their knowledge of alternative descriptions is shared with their interlocutor. By this logic, in the case of facts, children may have expected Percy to know the fact associated with the first novel object (e.g., "I got this for Christmas") when he had been present when this fact was introduced, but not when he had been in his house sleeping. Thus, only in the former condition could children have reasoned that it would have been uncooperative for Percy to refer to the first object using a second, distinct fact ("Can you give me the one from Mexico?"), and thus infer that he must want the other, previously-unreferenced object. Critically, however, Diesendruck and Markson (2001) argued that, unlike idiosyncratic facts, children expect object labels to be known by all competent speakers of their language, explaining why children made mutual exclusivity inferences regarding the second label even when they were taught the first object's label in Percy's absence. As evidence for this position, Diesendruck and Markson (2001) noted that at the end of their study, children often stated that Percy "knew the names of the toys we played with," (p. 635) even when he had been absent during the teaching of the first object labels.

Building on the approach of Diesendruck and Markson (2001), other studies have used the mutual exclusivity paradigm as a measure of whether children believe that their knowledge is shared with others. Together, these studies have concluded that, by the early preschool years, children have a sophisticated understanding of when others should share their linguistic and cultural knowledge (Diesendruck, 2012; Sabbagh \& Henderson, 2007). For example, studies 
using this method have argued that while children expect object labels and functions (e.g., spoons are for eating) to be known by other members of their community, they do not hold the same expectation about idiosyncratic facts (e.g., "I got this for Christmas") or proper nouns (Diesendruck \& Markson, 2001; Diesendruck et al., 2010; Diesendruck, 2005). These studies have also argued that children's beliefs about who shares their knowledge of object labels is constrained, and excludes speakers of other languages (Diesendruck, 2005), and speakers who are ignorant of object labels (e.g., a speaker who has called a cup "a ball," or a dog "a book;" Diesendruck et al., 2010).

Importantly, the conclusion from these previous studies — that young children have a sophisticated understanding of who shares their knowledge across different domains and different kinds of people — rests on the assumption that mutual exclusivity inferences are epistemically-mediated. However, as already noted, this issue has been the subject of significant debate, and is not resolved by the study of Diesendruck and Markson (2001). To understand why, consider again the scenario presented in their study, in which children learned that one novel object was called "a dax," and were then asked for "a bem" by a previously-absent Percy. As Diesendruck and Markson (2001) argue, children may have made this judgment by assuming that Percy knew that the first, labeled object was a dax, and thus that if he had wanted a dax he would have asked for it. Critically, however, children could also have made this judgment without any appeal to Percy's knowledge of the labeled object's name, by instead drawing on their own knowledge of this name and the pragmatics of the situation. For example, children may have reasoned that the name that they had learned for the labeled object was the conventional label of that object (i.e, the label that speakers of their language use to reference this object), generating a prescriptive expectation about how that object should be referenced by other 
speakers of their language, including Percy: i.e., he should called it "a dax". Children may have then applied this expectation when interpreting Percy's request, by reasoning that when Percy requested an object using a different label (“Can you give me the bem?"), he could not have wanted the labeled object and thus must want the previously-unlabeled object; Children could make this inference based either on a belief about how words refer (i.e., that words will label mutually exclusive sets of objects; Markman, 1990, 1991; Markman \& Wachtel, 1988) or on a belief that different linguistic forms arise from different referential intentions (Clark's "Principle of Contrast"; Clark, 1987, 2007). Thus, children could have guessed that bem likely labeled the second, previously-unlabeled object independent of whether they believed that Percy knew that the first object was called "a dax." Additionally, children may have indicated that Percy "knows the names of the toys we played with" at the end of the study because his repeated requests during the study (“Can you give me the bem?”) presupposed knowledge of object labels: a speaker should only ever request a bem if they know what a bem is.

By this alternative, non-epistemic account, children in Diesendruck and Markson's (2001) study did not select the second, previously-unlabeled object in response to Percy's request because they believed that Percy shared their knowledge of the first, labeled object's name. Instead, children may have held a normative expectation about how this object should be referenced by speakers of their language (e.g., that it should be called "a dax") - rooted in their own knowledge of this object's conventional name - which they applied when interpreting Percy's request. For instance, children may have reasoned: "Since Percy is speaking my language, he should ask for a dax if he wants the first object, because I know that dax is the single, conventional label for this object in my language. Thus, when Percy asks for a bem he must want the other object." According to this view, children may expect objects to be 
referenced by their conventional labels (e.g., that an object should be called a dax) without necessarily believing that all speakers of their language know these conventional forms of reference (e.g., believing that Percy knows that the object is called a dax).

Critically, this alternative explanation can also account for why children do not make mutual exclusivity inferences when interpreting novel words produced by speakers of another language (Diesendruck, 2005) or by ignorant speakers of their own language (Diesendruck et al., 2010). Children may recognize that conventions for how objects should be referenced in their language will not be followed by speakers of another language or by incompetent speakers of their own language. Thus, in both cases, children may understand that their own knowledge of an object's conventional label does not preclude that their interlocutor might use a different label to refer to that same object, such that they do not make mutual exclusivity inferences. This alternative account can also explain why children make mutual exclusivity inferences in response to requests involving object functions, e.g., in which a child is shown a spoon and a novel object, asked for "the one for making noise," and chooses the novel object (Diesendruck et al., 2010). Just as children may assume that each object has a single conventional label, they may also assume that it has a single conventional function or purpose (Casler \& Kelemen, 2005). Thus, children may think that an object whose function they know, like a spoon, should be referenced by this function as opposed to by another function: e.g., a speaker that wants a spoon should ask for "the one for eating" as opposed to "the one for making noise." Critically, in contrast to labels and functions, children may not assume that each object has a single, conventional idiosyncratic fact associated with it, explaining why a child might think that a speaker could request an object using a distinct fact (e.g., "Can you give me the one from Mexico?") from a fact that the child previously learned about that object from a different speaker (e.g., "My uncle gave this to me"). 
In sum, although previous findings are compatible with the idea that mutual exclusivity inferences are mediated by reasoning about the knowledge states of an interlocutor and assumptions regarding shared knowledge (e.g., that all object labels will be known by other competent speakers of a language), they are equally compatible with a non-epistemic account in which children's inferences are governed by their own knowledge of an object's label, their belief that this is the conventional label for this object in their language, and their recognition that this convention applies to their interlocutor. The present studies test these alternatives by manipulating the likely epistemic states of interlocutors and examining whether children's mutual exclusivity inferences can be predicted by their beliefs about whether their interlocutors share their knowledge of words.

\section{The Present Studies}

The present studies had two related goals. Our first goal was to explore whether mutual exclusivity inferences about word meanings require children to reason about the epistemic states of an interlocutor, or if instead, children's inferences are based on their own knowledge of conventional labels for objects. As reviewed above, previous studies have used mutual exclusivity as an index of children's beliefs about the scope of shared cultural knowledge, on the assumption that mutual exclusivity depends on attributing shared knowledge to an interlocutor; if this assumption turns out to be incorrect, the question of how children reason about shared knowledge would be re-opened. With this in mind, our second goal was to assess beliefs regarding shared knowledge independently of mutual exclusivity, to understand how learners might infer that a word they know will be known by their interlocutor.

To achieve our first goal, we explored whether children make mutual exclusivity inferences even in situations when their interlocutor should lack knowledge of relevant, 
alternative labels. According to Diesendruck and Markson (2001), children assumed that when they were taught a new word, like dax, a puppet who was absent nevertheless shared their knowledge of this label. We reasoned that although children might believe that a new label that they have been taught will be known by others (Csibra \& Gergely, 2009; Henderson \& Sabbagh, 2010), they should not make this assumption about words they have created in others' absence.

Guided by this idea, in Experiment 1 we employed the design of Diesendruck and Markson (2001), but manipulated whether the labeled object's name was introduced to children pedagogically ("This is a dax"), or if instead children participated in coining the name of the object ("What should we call it? Should we call it a dax or a zev?"). After the introduction of the label, the puppet — who had either previously been present or absent — asked the child for an object using a new, distinct label (“Can you give me the bem?"), and we recorded the child's choice of object (Figure 1). We reasoned that if children's selection of the second, previouslyunlabeled object derives from their assumption that the puppet knows the labeled object's name (epistemic accounts), they should not reliably select this object when the labeled object's name was coined in the puppet's absence, because the puppet should not know this name. Further, we reasoned that if mutual exclusivity inferences are based on epistemic reasoning of this kind, they should be predicted by children's theory of mind ability, which we measured after the task.

In Experiments 2 and 3, we directly asked preschoolers and adults whether the puppet knows the labeled object's name (“Does Percy know we call this a dax?") after it had been coined (Experiment 2) or taught (Experiment 3) in the puppet's presence or absence, and tested whether participants' responses predicted their later choice of objects. This method allowed us to directly test whether mutual exclusivity inferences are contingent on attributing knowledge of an object's label to an interlocutor (our first goal). We also examined the factors that might affect 
Mutual Exclusivity and Conventionality

participants' beliefs that their knowledge of the object labels will be shared with their interlocutor (our second goal), by testing whether 1) participants were more likely to indicate that Percy "knows" the labeled object's name when he was present during its introduction compared to when he was absent, 2) when the label had been taught (Experiment 3) as opposed to coined (Experiment 2), and 3) as a function of their theory of mind ability, which we measured in both experiments (Sabbagh \& Henderson, 2007). Finally, Experiment 4 followed up on the previous experiments to further explore why children might make mutual exclusivity inferences without attributing shared knowledge of an alternative label to their interlocutor. 

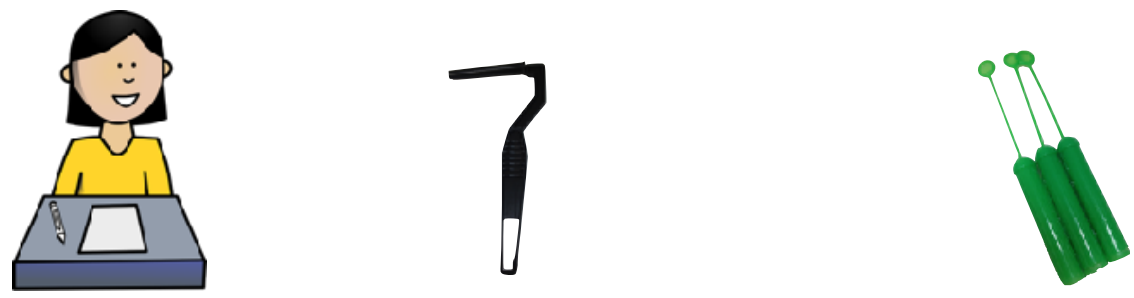

Pedagogical (Exp 1 \& 3): E: "...This is a dax"

Coinage (Exp 1 \& 2): E: "...What should we call it? Should we call it a dax or a zev?"

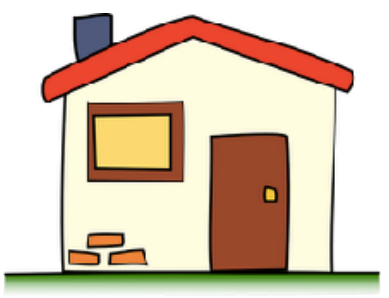

Coinage (Exp 4): E: “...What should we call it?

Can you make up a name for it?"
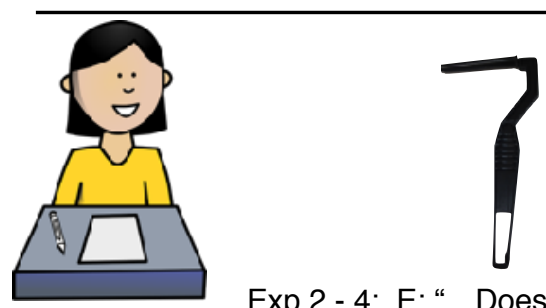

Exp 2- 4: E: “...Does Percy know we call this a [dax / child's coinage]?"
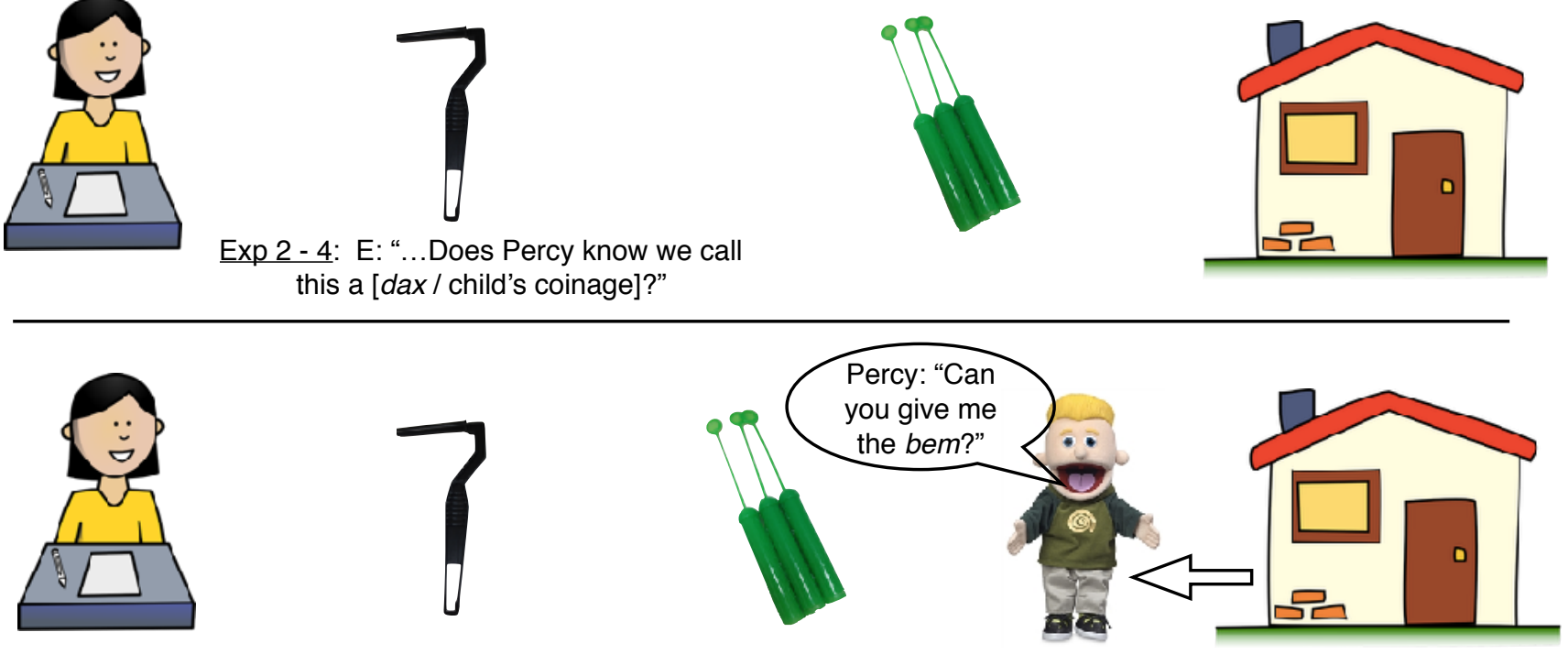

Figure 1. An illustration of the different phases of a critical trial from the Puppet Absent conditions of Experiments 1 through 4. Note that in the Puppet Present conditions, Percy was outside of his house for the entirety of the trial 


\section{Experiment 1}

The goal of Experiment 1 was to replicate the findings of Diesendruck and Markson (2001) and to test whether these results persist when novel labels are coined during the experiment, rather than taught to children pedagogically. We reasoned that if children's mutual exclusivity inferences depend on the assumption that Percy knows the name of the labeled object, then they should fail to make these inferences when the label is coined in his absence.

\section{Method}

Participants. Sixty-six monolingual English-speaking children $(M=3.91$ years; range $=$ [3.03 - 4.87]; 32 females) participated in one of four conditions. Thirty-four children participated in the Pedagogical conditions, including 16 in the Puppet Present condition $(M=3.96$ [3.20 4.46]; 8 females) and 18 in the Puppet Absent condition ( $M=3.84$ [3.03 - 4.55]; 9 females). Thirty-two children participated in the Coinage conditions, including 16 in the Puppet Present condition ( $M=3.81$ [3.21 - 4.77]; 7 females) and 16 in the Puppet Absent condition ( $M=4.03$ [3.32 - 4.87]; 8 females). Ten additional children were tested but excluded from analyses due to experimenter error (2) or unwillingness to participate (8). Our sample size was based on Diesendruck and Markson (2001), who enrolled about 16 participants per cell. This gave us more than $90 \%$ power for detecting a large effect size (an odds ratio of 3 ) in our logistic regression models, at a 0.05 significance level (see Supplementary Material). Participants were recruited from the San Diego, CA area, and were tested either in lab or at a children's museum. All children received a token gift for participating.

Materials and Procedure. All children first completed a word learning task and then received a theory of mind battery (Wellman \& Liu, 2004), as described below. 
Word Learning Task. There were four between-subjects conditions. In the two Pedagogical conditions, which aimed to provide as best as possible a direct replication of Diesendruck and Markson (2001), children were taught novel labels for novel objects, either in the presence or absence of a puppet. In the Coinage conditions children participated in coining the label of novel objects with the experimenter, again either in the puppet's presence or absence.

In all conditions, participants sat at a table with an experimenter and a doll house. Percy (controlled by a second, unseen experimenter) was then introduced to the child. In the Puppet Present conditions, Percy was introduced as being familiar to the experimenter. The experimenter said, "Hi Percy! How are you? Let me introduce you to my friend, [child's name]. We are here to look at some things I brought." Percy indicated that he would stay and watch: “Oh that sounds fun! I'll stay here and play with you guys!” Percy then stayed outside of his house to observe and comment on the experimenter and child's interaction.

In the Puppet Absent conditions, the experimenter indicated that $\mathrm{s}(\mathrm{he})$ did not know Percy. After Percy emerged from his house, he said, "Hi there! Who are you, and what are you doing here?" and the experimenter replied, “I'm [experimenter's name] and this is my friend [child's name]. We are here to look at some things I brought. Who are you?" Percy then said "I'm Percy, and this is my house! I'll let the two of you play now. I'm going to take a nap. Don't worry about talking loudly because I can't hear anything that goes on outside when I'm in my house." To reinforce that Percy could not hear from inside his house, the experimenter said, “Let's see if Percy wants to keep playing. Let's call out to Percy. Percy! Percy! ... Oh, I forgot that Percy can't hear us when he's in his house. Let me knock on the door to get him to come out. Knock, knock!” Percy then emerged and reiterated his desire to sleep: “No, I'm kind of tired and want to rest. Have fun! It was nice to meet you, but now I'm going back inside my house." 
In the Pedagogical conditions, the experimenter then turned to the child and said, "Let's look at the neat things I brought with me, okay?" The experimenter therefore presupposed some familiarity with the objects that (s)he would later teach labels for. In contrast, in the Coinage conditions, the experimenter indicated that s(he) was not familiar with these objects, to help make sense of why s(he) would later encourage the child to choose names for them: "I found some neat things today and I don't know what they are. Do you want to look at them with me?"

Critical Trials. In all conditions, the experimenter began each trial by bringing out two novel objects (see Supplementary Material). In the Pedagogical conditions, the experimenter taught the child the name of the labeled object: "Look at this one! Do you know what it's called? It's a [dax]! Okay? It's a $[d a x]$. This is a $[d a x]$." In the Coinage conditions, the experimenter encouraged the child to choose the name of the labeled object: "Look at this one! Hmm... (pauses). What should we call it? Should we call it a $[\mathrm{dax}]$ or a $[\mathrm{zev}]$ ?" The experimenter then ratified the label chosen by the child: "Okay, let's call it a [child's label]. Let's call it a [child's label]." In all conditions, the experimenter also made a generic comment about the other, unlabeled object, to equate attention toward each object ("Look at this one! It's neat. Isn't it cool? This is neat!"). Within each condition, there were four item orders that counterbalanced (1) which of the two objects was labeled, and (2) whether the labeled or unlabeled object was introduced first. The novel labels were each monosyllabic, legal English non-words (see Supplementary Material).

After the labeling phase of each trial, Percy requested an object using a distinct label from the labels that had been introduced during the labeling phase (emerging from his house just after the labeling phase ended in the Puppet Absent conditions; Figure 1): e.g., "Hey [child's 
name]! I want the [bem]! Can you give me the [bem]?" In the Puppet Absent conditions, Percy went back into his house to sleep after receiving the object.

There were six critical trials, involving 12 different novel objects. After the third trial in the Puppet Absent conditions, children were provided a reminder of Percy's absence and inability to hear: "Percy asks some funny questions, huh? And he sleeps a lot! Oh, don't worry. Remember, he can't hear us when he's inside of his house!" After the critical trials, Percy went back into his house and, following Diesendruck and Markson (2001), the experimenter asked, "Do you think Percy knows the names of the toys we played with?" In only the Puppet Absent conditions, children were also asked, "Do you think Percy could hear you from inside his house?" We coded children's response as "Yes," "No," or "Don't Know."

Theory of Mind Battery. All children received five items from the Wellman and Liu (2004) Theory of Mind battery which tested their beliefs that: 1) others will act on their own desires, 2) knowledge requires visual access, 3) others can have false beliefs about the contents of a container, 4) others will act on their own beliefs, and 5) others will act on their own false beliefs. Wellman and Liu's criteria were used to compute the proportion of trials that each child passed.

Analyses. Our dependent measure was whether participants selected the previouslyunlabeled object and therefore computed mutual exclusivity inferences. To test this, we compared children's performance to chance (50\%) using planned comparisons, and constructed mixed-effects logistic regressions using the LME4 package in R, to predict selection of the previously-unlabeled object as a function of our within- and between-subjects factors. For all analyses, interactions of interest were initially included, but were dropped if non-significant. We also mean-centered all continuous independent variables (i.e., Age, Theory of Mind), to 
minimize multicollinearity and increase the interpretability of model coefficients. For additional analyses, see Supplementary Material. Raw data and analyses scripts for all experiments reported here can be found at: http://osf.io/chmjt (Srinivasan, Foushee, Bartnof \& Barner, 2018).

\section{Results and Discussion}

We used a mixed effects logistic regression to predict children's choice of the unlabeled object on each trial (Labeled vs. Unlabeled), as a function of how the label was introduced (Label Introduction; Pedagogical vs. Coinage), whether Percy was present or absent when the label was introduced (Puppet Presence; Puppet Present vs. Puppet Absent), and the interaction between Label Introduction and Puppet Presence. The model also included Age and Theory of Mind score as fixed effects, and random intercepts for each subject. Because this model did not find a significant interaction between Label Introduction and Puppet Presence $($ Odds Ratio $=.81$, $95 \%$ Confidence Interval of Odds Ratio $=[.29,2.22]$, Wald $\left.\chi^{2}(1)=.18, p=.68\right)$, we reverted to a model without this term.

We found a significant effect of Theory of Mind $\left(\mathrm{OR}=1.63, \mathrm{CI}=[1.47,1.83], \chi^{2}(1)=\right.$ $75.25, p<.001)$, such that the odds of selecting the previously-unlabeled object were increased in children with higher Theory of Mind scores, a finding we return to below. However, there were no significant effects of Age $\left(\mathrm{OR}=1.00, \mathrm{CI}=[.96,1.05], \chi^{2}(1)=0, p=.96\right)$, Label Introduction (OR for Coinage condition $\left.=1.00, \mathrm{CI}=[.61,1.64], \chi^{2}(1)=0, p=.99\right)$, or Puppet Presence $\left(\mathrm{OR}\right.$ for Puppet Absent condition $\left.=1.06, \mathrm{CI}=[.65,1.74], \chi^{2}(1)=.06, p=.81\right)$. Replicating Diesendruck and Markson (2001), children in the Pedagogical conditions selected the previously unlabeled object reliably more often than chance - providing evidence that they made mutual exclusivity inferences both when Percy had been present when the labeled object's name was taught $(M=.65$, bootstrapped $95 \%$ Confidence Interval $=[.55, .74], t(15)=3.00, p<$ 
$.01)$ and when he had been absent $(M=.70[.61, .79], t(17)=4.11, p<.001)$. Critically, children responded similarly in the Coinage conditions: they selected the previously-unlabeled object reliably more than chance when Percy had been absent during the coinage of the labeled object's name $(M=.67[.55, .78], t(15)=2.83, p<.05)$, and at a similar rate when Percy had been present throughout the trial, though this did not reach significance $(M=.66[.48, .81], t(15)=$ $1.79, p=.09)$.

These results pose a challenge for epistemic accounts of mutual exclusivity inference. According to these accounts, children in Experiment 1 should only have made mutual exclusivity inferences if they reasoned that Percy knew the name of the first, labeled object (e.g., dax). Thus, to explain our findings, epistemic accounts would need to posit that children expected Percy to know the name of the labeled object even when this name was coined while he was sleeping (i.e., in the Coinage Puppet Absent condition). Lending some credence to this idea, we found that at the end of the word learning task, children often indicated that Percy "knows the names of the toys we played with," even when Percy had been absent during the introduction of the labeled object's name, similar to the findings of Diesendruck and Markson, 2001, Study 2, in which 63\% of children said Percy knew the names of the toys when he had been absent. In our study, this was true both in the Pedagogical conditions (Puppet Present: 93.8\%; Puppet Absent: 72.2\%) and to a lesser extent in the Coinage conditions (Puppet Present: 73.3\%; Puppet Absent: 53.3\%). While these judgments may reflect children's belief that Percy knew the labels coined in his absence, it is also possible that children's assessment reflected Percy's general familiarity with labels in the experiment - since he used them in his requests - but not necessarily Percy's knowledge of the specific labels that were coined in his absence. 
It was interesting that children with higher Theory of Mind scores were more likely to choose the previously-unlabeled object. In principle, this could support epistemic accounts of mutual exclusivity; children with stronger theory of mind may have been better able to judge that Percy knew the labeled object's name, allowing them to infer that when Percy used a second, distinct label, he must have wanted the other, previously-unlabeled object. On this interpretation, we might expect children with stronger theory of mind to have been less likely to make mutual exclusivity inferences in the Coinage Puppet Absent condition, since in this condition, the puppet would be unlikely to have knowledge regarding the labeled object's name. However, a post-hoc analysis found no significant interactions involving Theory of Mind, Puppet Presence, and Label Introduction, suggesting that the effect of Theory of Mind was equally strong in the Coinage Puppet Absent condition as in the other three conditions (see Supplementary Material). We return to this issue when discussing the results of Experiment 2.

\section{Experiment 2}

Experiment 1 found that - even when children have just coined a new label for an object while another speaker was absent - they still expect that when the speaker uses a contrasting label, it will refer to a different object, making a mutual exclusivity inference. These findings can be explained by epistemic accounts of mutual exclusivity if children attribute knowledge of nouns that they have coined to other speakers. To test this possibility, Experiment 2 directly probed beliefs about Percy's knowledge of the newly coined labels: after participants selected a name for the labeled object ("Should we call it a dax or a zev?"), we asked them if they thought Percy knew this label ("Does Percy know we call this a $[d a x]$ ?"). Otherwise, the experiment was identical to the Coinage conditions of Experiment 1 (Figure 1). Of interest was whether variation in participants' judgment that Percy "knows" the coined label would predict their 
subsequent mutual exclusivity inferences. By independently assessing beliefs about Percy’s knowledge, we also explored how beliefs about shared knowledge of a label might vary as a function of whether Percy was present or absent during the label's introduction, and as a function of children's developing theory of mind. To ensure variability in theory of mind ability, we enrolled a wide age range of children, and also compared children's responses to those of adults.

\section{Method}

Participants. Sixty-seven monolingual English-speaking three- to five-year-old children $(M=4.48$ years; range $=[3.14-5.91] ; 32$ females $)$ participated, including 34 "younger" children $(M=3.86[3.14-4.50] ; 17$ females $)$ and 33 "older" children $(M=5.11[4.52-5.91] ; 15$

females). Additionally, 32 English-speaking adults participated ( $M=23.51$ [18.50 - 49.80]; 17 females). Roughly half of the participants in each age group participated in the Puppet Absent condition, and half in the Puppet Present condition. Five additional children were tested but were excluded from the study, due to experimenter error (2), parental interference during testing (2), or unwillingness to participate (1). All child participants were recruited from the Berkeley, CA area, and were tested either in lab or a quiet area of a children's museum. All children received a token gift for their participation. All adult subjects were recruited through the University of California Department of Psychology subject pool in exchange for course credit.

Materials and Procedure. All aspects of the word learning task were identical to the Coinage conditions of Experiment 1 except that participants were asked to indicate whether Percy knew the name of the object they had just coined on each trial (Figure 1). Specifically, after repeating the novel label chosen by the participant (e.g., "Okay, let's call it a [dax]. Let's call it a $[d a x]$ "), the experimenter pointed to the labeled object and asked the participant: "Does Percy know we call this a [dax]?" We coded responses as "Yes," "No," and "Don't Know." To 
make it clear that Percy had attended to the coined label in the Puppet Present condition, Percy explicitly repeated this label — e.g., "Okay, let's call it a $[$ dax $]$ !" — before participants were asked about whether Percy knew the label (following Diesendruck and Markson, 2001). Other than this, the trials proceeded just as in Experiment 1. All children received the Theory of Mind battery after completing the word learning task.

Analyses. For purposes of analyses, judgments of whether Percy knew the labeled object's name were recoded to contrast "Yes" responses vs. other responses (i.e., "No" and "Don't Know" responses were collapsed). In addition to the analyses conducted in Experiment 1, we report planned t-tests that test whether participants in each age group indicated that Percy knows the name of the labeled object more often in the Puppet Present compared to the Puppet Absent condition. Further, we included judgments of Percy's knowledge of the labeled object's name as a predictor in logistic regression models of participants' object choices. Finally, we report a linear model that predicts children's judgments that Percy knows the labeled object's name, averaged across trials. For the linear model, we report coefficients, confidence intervals of coefficients, and t-tests and p-values for each coefficient (using the $\mathrm{lm}$ function in R). 


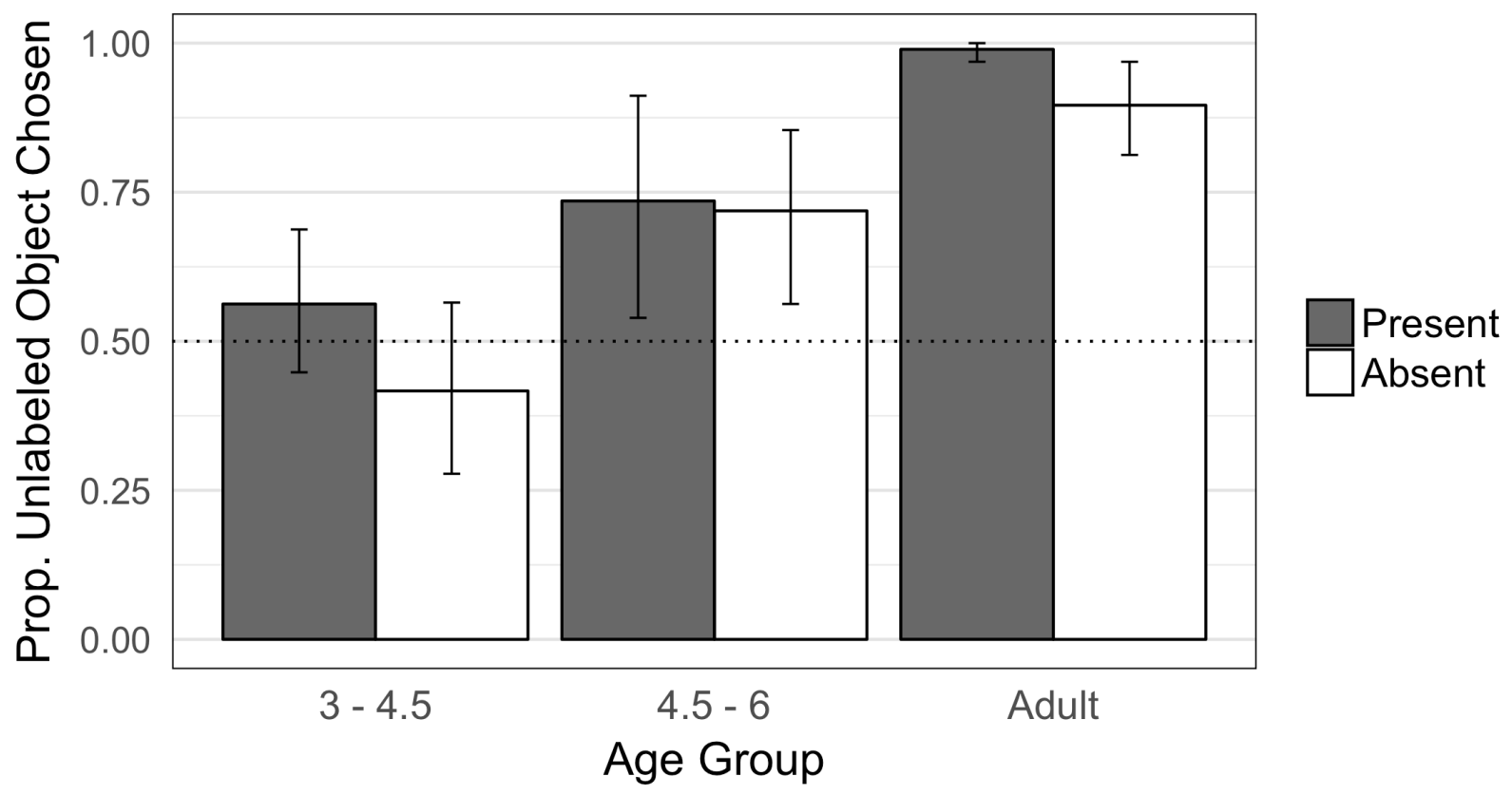

Figure 2. The proportion of trials in which participants from the three age groups selected the previously-unlabeled object in response to Percy's request in the Puppet Present and Puppet Absent conditions of Experiment 2. Error bars represent bootstrapped 95\% confidence intervals.
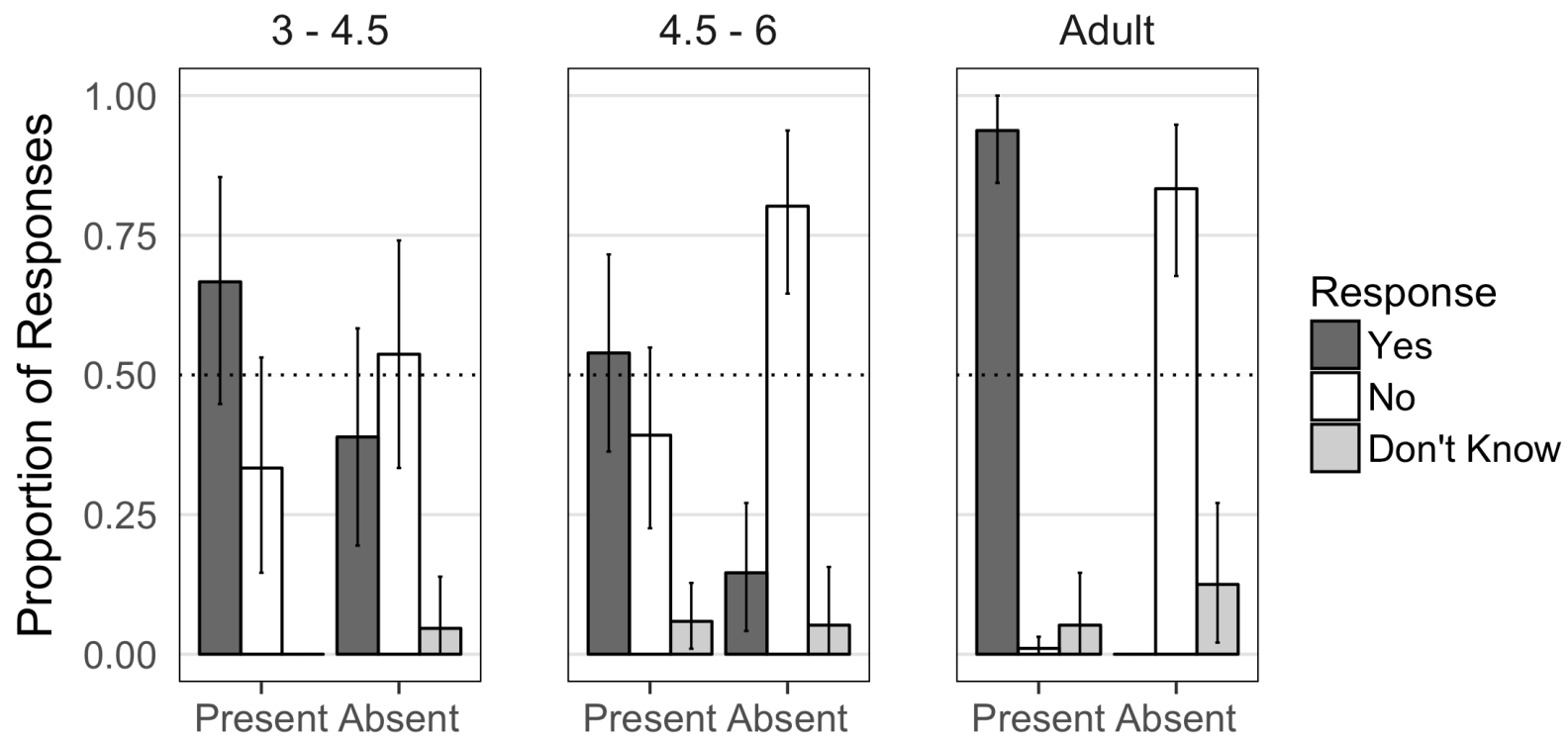
Figure 3. Proportion of "Yes," "No," and "Don't Know" answers in response to whether Percy knew the labeled object's name in the Puppet Present and Puppet Absent conditions of Experiment 2. Error bars represent bootstrapped 95\% confidence intervals.

\section{Results and Discussion}

We organize this section according to analyses of participants' (1) object choices (Figure 2), and (2) judgments of whether Percy knew the labeled object's name (Figure 3).

Analyses of participants' object choices. We used mixed effects logistic regressions to predict choices of the unlabeled object, with separate models for adults and children, grouping together the younger and older children and treating children's age as a continuous variable (we also conducted separate models for the younger and older children, and found broadly similar results; see Supplementary Material). The model for children included a factor for Puppet Presence (whether Percy was Present or Absent), Puppet Knowledge (whether children said Percy knew the labeled object's name or not), Age, and Theory of Mind. The model for adults only included Puppet Presence, leaving out Puppet Knowledge, because adults' judgments of whether Percy knew the labeled object's name patterned almost perfectly with whether Percy was Present or Absent (Figure 3). Both models included random intercepts for participants.

Beginning with adults, we did not find a significant effect of Puppet Presence $(\mathrm{OR}=.08$, $\left.\mathrm{CI}=[0,1.77], \chi^{2}(1)=3.40, p=.07\right)$, indicating that Percy's presence or absence during the coinage of the name of the labeled object — which tracked adults' beliefs that Percy shared their knowledge of this label — was not significantly related to adults' choices of the unlabeled object. Planned t-tests indicated that adults selected the previously-unlabeled object reliably more often than chance regardless of whether Percy had been present throughout the trial $(M=$ $.99[.97,1.00], t(15)=47.00, p<.001)$, or had been absent when the name of the labeled object 
was coined $(M=.90[.81, .97], t(15)=9.27, p<.001$; Figure 2$)$. Thus, adults made mutual exclusivity inferences in response to Percy's requests even when they had overwhelmingly indicated that Percy did not share their knowledge of the labeled object's name (Figures 2 and 3), posing a direct challenge to epistemic accounts of mutual exclusivity inference.

Assessments of Percy's knowledge of the labeled object's name was also not a significant predictor of children's object choices $\left(\mathrm{OR}=.89, \mathrm{CI}=[.36,2.19], \chi^{2}(1)=.07, p=\right.$ $.80)$, nor was Puppet Presence (OR for Absent condition $=0.45, \mathrm{CI}=[.13,1.42], \chi^{2}(1)=1.85, p$ $=.17)$, Theory of Mind $\left(\mathrm{OR}=1.15, \mathrm{CI}=[.92,1.46], \chi^{2}(1)=1.49, p=.22\right)$, or Age $(\mathrm{OR}=1.07$, $\left.\mathrm{CI}=[1.00,1.15], \chi^{2}(1)=3.41, p=.06\right)$. Thus, children's beliefs regarding whether Percy knew the labeled object's name was not significantly related to their interpretation of his use of a second, distinct label. Planned t-tests found that the older children selected the previously unlabeled object reliably more often than chance - and thus made mutual exclusivity inferences - both when Percy had been present throughout the trial $(M=.74[.54, .90], t(16)=2.45, p<$ $.05)$, and when he had been absent $(M=.72[.56, .85], t(15)=2.84, p<.05)$. In contrast, younger children's selection of the previously-unlabeled object did not differ significantly from chance in either the Puppet Present condition $(M=.56[.44, .69])$ or the Puppet Absent condition $(M=.42[.27, .56]) .{ }^{1}$ Thus, just like the adults, the older children reliably made mutual exclusivity inferences even when they had most often judged that Percy did not know the labeled

\footnotetext{
${ }^{1}$ It was surprising that younger preschoolers in Experiment 2 (aged 3.14 to 4.50 years) failed to make mutual exclusivity inferences given that children from an overlapping age range in Experiment 1 (3.03 - 4.87) generally made them under similar conditions. This discrepancy could be attributed to the increased memory demands of Experiment 2, which added an intervening question about Percy's knowledge of the labeled object's name. If children did not retain memory of the labeled object's name from the time it was introduced until Percy's request, they would not be able to determine whether Percy's request employed a distinct label or not, and thus would not be expected to make a mutual exclusivity inference on either epistemic or non-epistemic accounts.
} 
object's name (Figures 2 and 3). These findings are difficult to explain for epistemic accounts in which mutual exclusivity inferences depend on reasoning that an interlocutor knows the name of a contrasting object (e.g., like dax), and would have used this label had they wanted that object. The fact that Theory of Mind was not a significant predictor of children's object choices is also difficult to explain for epistemic accounts, and suggests that the effect of Theory of Mind found in Experiment 1 is not reliable.

Together, these results suggest that older children's and adults' own knowledge of the name for the labeled object - rather than their beliefs about Percy's knowledge of this name must have been sufficient to support their mutual exclusivity inferences. However, they leave open exactly why this occurred. In particular, it is unclear why children and adults would think that Percy's label (e.g., bem) could not refer to the labeled object, given that the name of the labeled object (e.g., dax) was ostensibly made up. We return to this issue in Experiment 4.

Analyses of participants' judgments of Percy' knowledge. The findings described above indicate that participants' judgments of whether Percy knew the name for the labeled object were independent of their tendency to make mutual exclusivity inferences. This implies that previous studies that have used mutual exclusivity to make claims about how children reason about shared knowledge may have been in error. To begin to address how learners might infer that a word that they know will be known by others, we explored what factors predicted participants' judgments of whether Percy knew the labeled object's name. Beginning with adults, and as noted above, Percy's presence during the coinage of the labeled object's name was strongly related to their beliefs about Percy's epistemic states (Figure 3). Specifically, adults never indicated that Percy knew the name of the labeled object when he had been absent when the label was coined $(M=0)$, but almost always judged that Percy knew the label when he had 
been present and had himself used this label $(M=.94[.84,1.00])$, providing strong evidence of his knowledge.

To understand which factors related to children's beliefs that Percy shared their knowledge of the labeled object's name, we grouped children from the older and younger age groups together, and used a linear model to predict children's average judgments, across trials, that Percy knew the labeled object's name. The model tested the effect of Puppet Presence, Age, Theory of Mind and the interaction between Puppet Presence and Theory of Mind. Because this model did not detect a significant interaction between Puppet Presence and Theory of Mind $(B=$ $-.04, \mathrm{CI}=[-.11, .02], t(61)=-1.30, p=.20)$, we reverted to a model without this term.

This analysis yielded a significant effect of Puppet Presence $(B=-.30, \mathrm{CI}=[-.49,-.11]$, $t(62)=-3.08, p<.005)$, as children, like adults, were less likely to say that Percy knew the labeled object's name when it had been coined while he was absent compared to when he was present (Figure 3). Planned t-tests indicated that older children rarely indicated that Percy knew the name of the labeled object when he had been absent $(M=.15, \mathrm{CI}=[.04, .27])$, but were significantly more likely to judge that Percy knew the label when he had been present $(M=.54$ $[.35, .72], t(27.38)=3.57, p<.01)$, though they were notably conservative about attributing knowledge to Percy even when he had been present. The younger children also said that Percy knew the name of the first object more often when he was present $(M=.67[.45, .89])$ than when he was absent $(M=.39[.19, .61])$, but this difference was not statistically significant $(t(31.95)=$ $1.79, p=.08)$

Strikingly, the linear model also yielded a significant effect of Theory of Mind $(B=-.46$, $\mathrm{CI}=[-.84,-.08], t(62)=-2.43, p<.05)$ over and above Age $(B=0, \mathrm{CI}=[-.02, .01], t(62)=-$ $0.87, p=.39$ ), which reflected that children with higher Theory of Mind scores were overall less 
likely to say that Percy knew the name of the labeled object (Figure 4). As noted above, this effect of Theory of Mind did not significantly interact with condition (Puppet Present vs. Puppet Absent). To our knowledge, this finding provides the first empirical support for the idea that children with weaker theory of mind may assume that words they know are known by others, while children with stronger theory of mind might override this belief (Sabbagh \& Henderson, 2007).

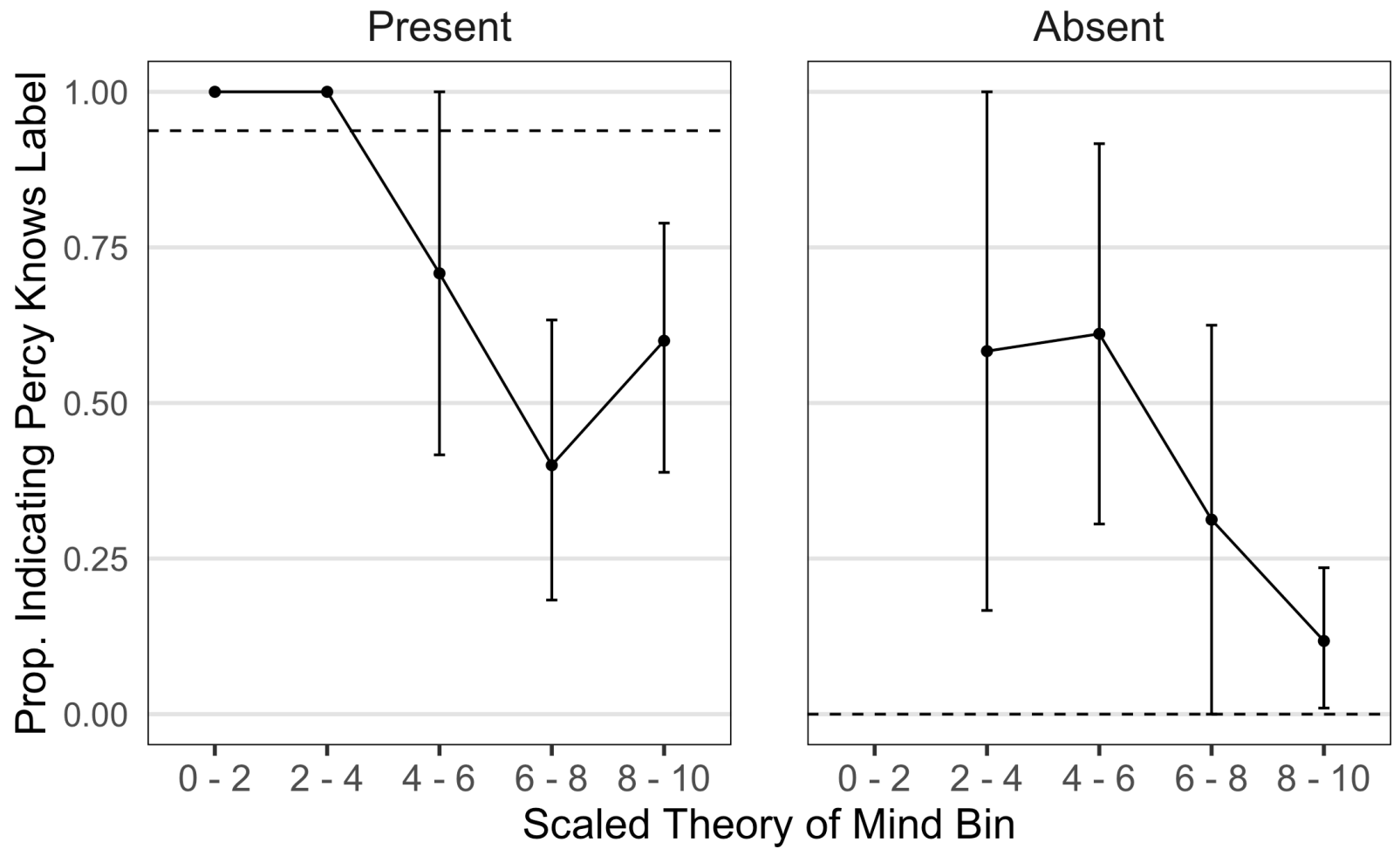

Figure 4. Relation between Theory of Mind score and assessments of Percy's knowledge in Experiment 2. The solid black line and dots indicate the proportion of trials in which children indicated that Percy "knows" the name of the first object, as a function of Theory of Mind score. The dashed red line indicates the proportion of trials in which adults said that Percy "knows" the name of the first object. Error bars indicate bootstrapped confidence intervals.

\section{Experiment 3}


Older preschoolers and adults in Experiment 2 often indicated that Percy did not know the name of the labeled object when it had been coined in his absence (e.g., dax), but still made mutual exclusivity inferences in response to his use of a contrasting label (e.g., bem). Contrary to previous claims, this finding suggests that mutual exclusivity inferences do not require children or adults to attribute knowledge of object labels to their interlocutors. However, it leaves open the conditions in which children might actually believe that other speakers will share their knowledge of labels. For example, it is possible that children and adults might expect that labels that they have been taught - as opposed to labels that they have coined - will be known by other speakers of their language (Diesendruck, 2012; Diesendruck \& Markson, 2001). To test this, in Experiment 3 we taught three- to five-year-olds and adults a name for the labeled object (e.g., "This is a dax") while Percy was either present or absent, and then asked participants whether Percy knew this label (e.g., "Does Percy know we call this a dax?”). Otherwise, the experiment was identical to the Pedagogical conditions of Experiment 1 (Figure 1).

We were interested in whether participants would indicate that Percy knows the name of the labeled object even when he had been absent when this label was taught, and thus whether learners might assume that labels they have been taught will be known by other speakers of their language. As before, we also explored whether participants' belief that Percy knew the labeled object's name would predict their tendency to make mutual exclusivity inferences (epistemic accounts) or if instead participants might make mutual exclusivity inferences independently of their beliefs about Percy's knowledge (non-epistemic accounts), based on their own knowledge of an object's label.

\section{Method}


Participants. Sixty-six monolingual English-speaking three- to five-year-old children ( $M$ $=4.46$ years; range $=[3.04-5.93] ; 35$ females $)$ participated in the study, including 32 "younger" children ( $M=3.82$ [3.04 - 4.55]; 16 females) and 34 "older" children $(M=5.07$ [4.56 - 5.93]; 19 females). Additionally, 34 English-speaking adults participated ( $M=21.97$ [18.18 - 50.72]; 17 females). Roughly half of the participants in each age group participated in the Puppet Absent condition, and half in the Puppet Present condition. Three additional children were tested but were excluded from the study, due to experimenter error (1) or unwillingness to participate (2). Child and adult participants were recruited, tested, and compensated as in Experiment 2.

Materials and Procedure. The word learning task was identical to Experiment 2 except that participants were taught the name of the labeled object, instead of coining this name (Figure 1). Specifically, just as in the Pedagogical conditions of Experiment 1, the experimenter named the labeled object by pointing to it and saying "Look at this one! Do you know what it's called? It's a $[d a x]$ ! Okay? It's a $[d a x]$. This is a $[d a x]$." After this, the experimenter pointed to the object and asked the participant: "Does Percy know we call this a $[$ dax $]$ ?"

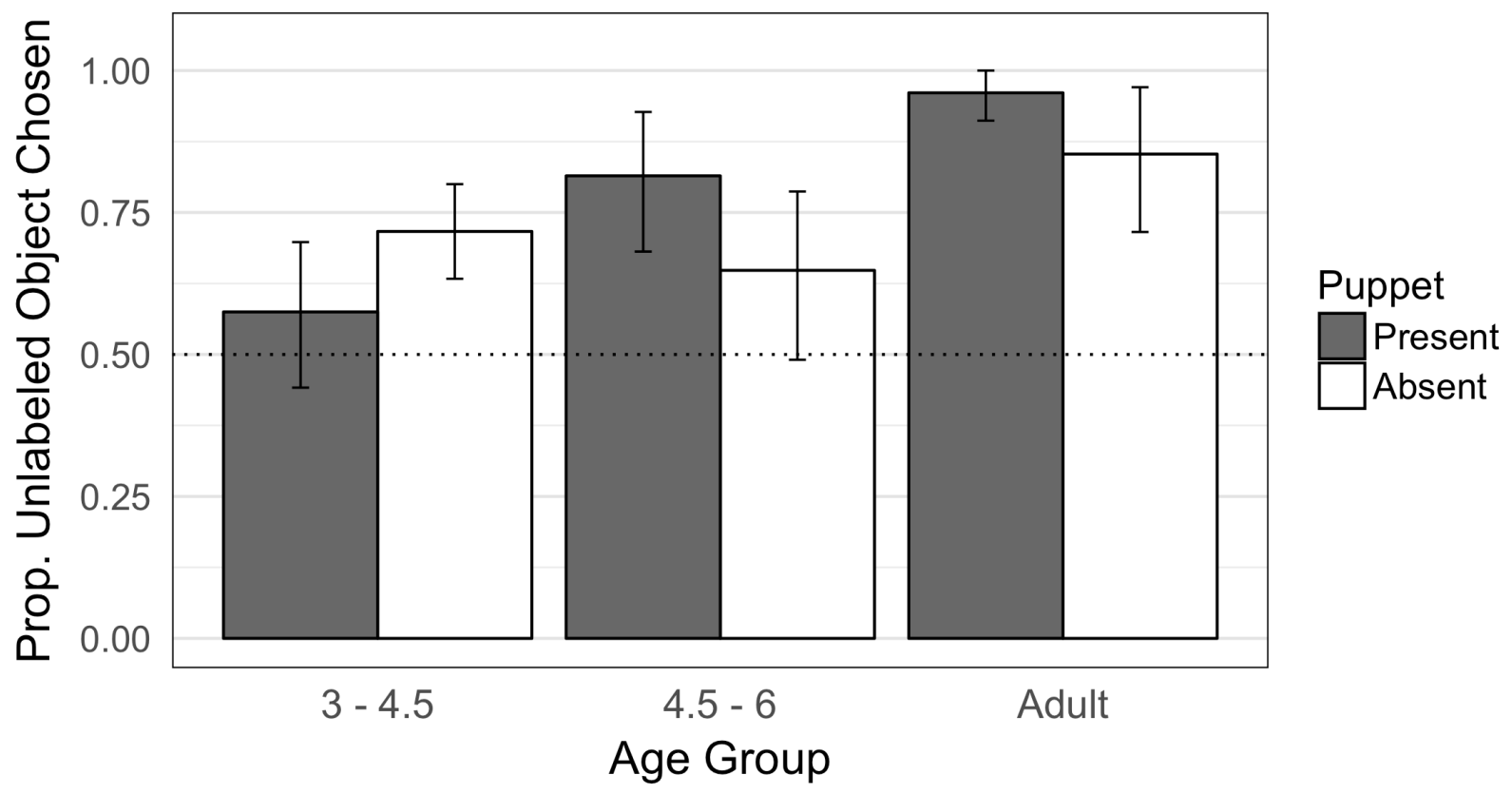


Figure 5. The proportion of trials in which children and adults selected the previously-unlabeled object in Experiment 3. Error bars represent bootstrapped 95\% confidence intervals.
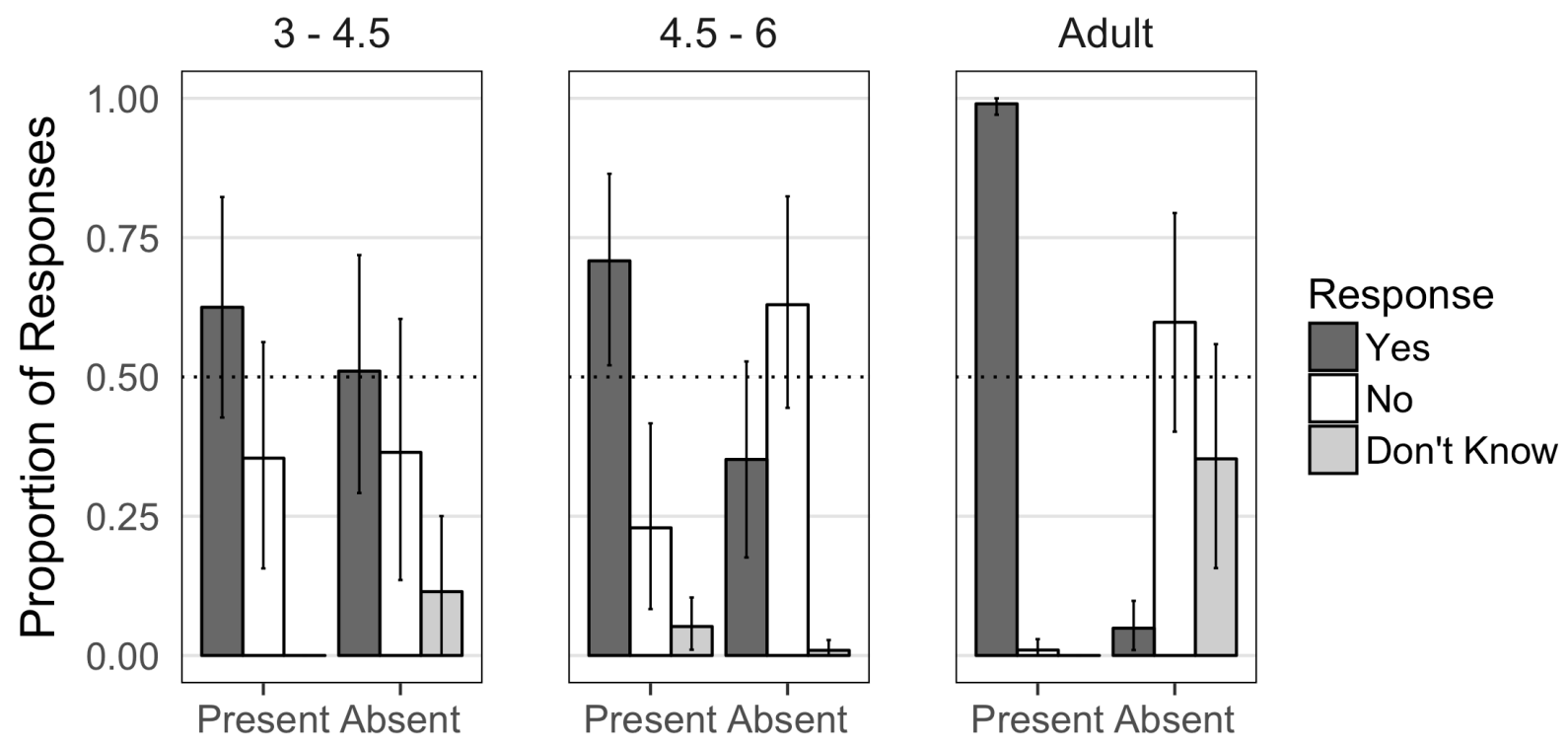

Figure 6. Responses to whether Percy knew the labeled object's name in Experiment 3. Error bars indicate bootstrapped $95 \%$ confidence intervals.

\section{Results and Discussion}

We organize this section according to analyses of participants' (1) object choices (Figure 5), and (2) judgments of whether Percy knew the labeled object's name (Figure 6).

Analyses of participants' object choices. We again used mixed effects logistic regressions to predict choices of the unlabeled object, with separate models for adults and children, grouping together the younger and older children (see Supplementary Material for additional analyses). The model for children included a factor for Puppet Presence, Puppet Knowledge, Age and Theory of Mind. The model for adults only included Puppet Presence, and not Puppet Knowledge, because the latter was predicted nearly perfectly by the former in adults (Figure 6). Both models also included a random intercept for each participant. 
Beginning with adults, we did not find a significant effect of Puppet Presence $(\mathrm{OR}=.34$, $\left.\mathrm{CI}=[.01,33.89], \chi^{2}(1)=.26, p=.61\right)$, indicating that Percy's presence during the teaching of the name of the labeled object — which tracked adults' beliefs that Percy shared their knowledge did not significantly affect their object choices. Planned t-tests indicated that adults chose the previously-unlabeled object reliably more than chance regardless of whether Percy had been present for the teaching of the labeled object's name $(M=.96[.91,1.00], t(16)=20.27, p<$ $.001)$, or had been absent when the label was taught $(M=.85[.73, .96] ; t(16)=5.54, p<.001)$. Thus, just as in Experiment 2, adults made mutual exclusivity inferences in response to Percy's requests even when they had also overwhelmingly indicated that Percy did not share their knowledge of the labeled object's name (Figures 5 and 6), contrary to epistemic accounts of mutual exclusivity inference.

Similar to adults, our model for children did not detect significant effects of Puppet Presence $\left(\mathrm{OR}=.98, \mathrm{CI}=[.40,2.33], \chi^{2}(1)=0, p=.97\right)$ or Puppet Knowledge $(\mathrm{OR}=1.58, \mathrm{CI}=$ $\left.[.75,3.32], \chi^{2}(1)=1.48, p=.22\right)$, nor did it yield significant effects of Age $(\mathrm{OR}=1.02, \mathrm{CI}=$ $\left.[.97,1.08], \chi^{2}(1)=.58, p=.45\right)$ or Theory of Mind $\left(\mathrm{OR}=1.00, \mathrm{CI}=[.81,1.24], \chi^{2}(1)=0, p=\right.$ .97). Like the adults, the group of older children selected the previously-unlabeled object reliably more often than chance when Percy had been present throughout the trial $(M=.81[.68, .94]$, $t(15)=4.73, p<.001)$, and there was a non-significant trend to select the previously-unlabeled object when Percy had been absent when the label had been taught $(M=.65[.49, .79] ; t(17)=$ $1.86, p=.08$; Figure 5). Younger children's selection of the previously-unlabeled object did not differ significantly from chance when Percy had been present for the teaching of the labeled object's name $(M=.57[.45, .70] ; t(15)=1.08, p=.30)$, but was significantly above chance when Percy had been absent $(M=.72[.64, .80] ; t(15)=4.86, p<.001)$. In sum, as in Experiment 
2, we found that younger and older children's tendency to select the previously-unlabeled object in response to Percy's request - which occurred reliably more often than chance in some conditions - was not contingent on their belief that Percy shared their knowledge of the labeled object's name, nor was it significantly related to their theory of mind ability.

Together, these findings suggest that for both children and adults, mutual exclusivity inferences do not require reasoning about an interlocutor's knowledge of an alternative word. Instead, children's and adults' mutual exclusivity inferences appear to be based on their own knowledge. For example, children and adults may have assumed that the name that they had learned for the labeled object was the conventional name of that object, yielding a prescriptive expectation about how that object should be referenced by other speakers of their language, including Percy. Children and adults may have then inferred that when Percy requested an object using a different label (e.g., "Can you give me the bem?"), he could not have been asking for the labeled object and must instead want the previously-unlabeled object, based on their belief that different words will pick out different referents (Clark, 1987, 2007; Markman, 1990, 1991; Markman \& Wachtel, 1988). ${ }^{2}$

\footnotetext{
${ }^{2}$ The forced-choice nature of the tasks presented in this paper raise the issue of whether participants actually form a genuine belief about the meaning of Percy's label or whether they might only select the previously-unlabeled object because they are forced to make a response. In an additional experiment (modeled after Experiment 3, Puppet Absent condition) we gave a new set of adult participants the additional options of indicating either that they did not know what Percy's label referred to, or indicating graded uncertainty in their belief (see Supplementary Material). We found that participants indicated that they "don't know" which object Percy's label referred to on $31 \%$ of trials; On the remaining trials, participants expressed a strong belief that Percy's label referred to the previously-unlabeled object. Proponents of an epistemic account could argue that when participants indicated uncertainty with respect to which Percy's label referred to, they did so because they believed that Percy did not know the labeled object's name (participants said that Percy knew the labeled object's name on only $8 \%$ of trials). However, it is also possible that participants were simply conservative about making a response that went beyond the evidence they had observed - which all mutual exclusivity inferences require regardless of their beliefs about Percy's knowledge. See Supplementary Material for additional discussion.
} 
Analyses of participants' judgments of Percy's knowledge. Here, we explore what factors predicted participants' beliefs about whether Percy shared their knowledge of the name of the labeled object (Figure 6). As noted above, adults almost never indicated that Percy knew the name of the labeled object when he had been absent when this label was taught $(M=.05[.01$, .10]), providing a direct challenge to the idea that people expect labels they been taught to be known by other speakers of their language (Diesendruck, 2012). As in Experiment 2, Percy's presence during the teaching of the labeled object's name was sufficient to lead adults to attribute knowledge of this label to Percy, which they did at ceiling $(M=.99[.97,1.00])$.

To understand what factors predicted children's belief that Percy "knows" the name of the labeled object, we used a linear model to predict children's judgments of shared knowledge — again grouping together the younger and older children — based on Puppet Presence, Theory of Mind, the interaction between Puppet Presence and Theory of Mind, and Age, with random intercepts for participants. This analysis yielded a significant effect of Puppet Presence $(B=-.32$, $\mathrm{CI}=[-.52,-.12], t(59)=-3.20, p<.01)$, as children, like adults, were overall less likely to say that Percy knew the name of the labeled object when he was absent when it was taught, compared to when he was present. Like the adults, older children rarely indicated that Percy knew the labeled object's name when he had been absent $(M=.35[.17, .53])$, challenging the idea that children expect labels they've been taught to be known by other speakers (Diesendruck, 2012). Older children were significantly more likely to judge that Percy knew the label when he had been present, compared to when he had been absent $(M=.71[.53, .88], t(31.99)=2.76, p<$ $.05)$. In contrast to the older children and adults, the younger children were not significantly more likely to attribute knowledge of the labeled object's name to Percy when he was present $(M$ $=.62[.42, .81])$ compared to when he was absent $(M=.51[.30, .72] ; t(29.94)=.87, p=.39)$. 
Interestingly, while the main effect of Age $(B=-.01, \mathrm{CI}=[-.02,0], t(59)=-1.23, p=.23)$ and Theory of Mind $(B=.01, \mathrm{CI}=[-.05, .07], t(59)=.30, p=.77)$ did not reach significance, the interaction between Puppet Presence and Theory of Mind was significant $(B=-.09, \mathrm{CI}=[-.17,-$ $.01], t(59)=-2.28, p<.05)$. This interaction reflects that children with higher Theory of Mind scores were less likely to say that Percy knew the labeled object's name in the Puppet Absent condition, compared to in the Puppet Present condition (Figure 7). Thus, theory of mind may be especially important for recognizing when a label one has learned may not be known by others, such as when others were absent during the learning episode.

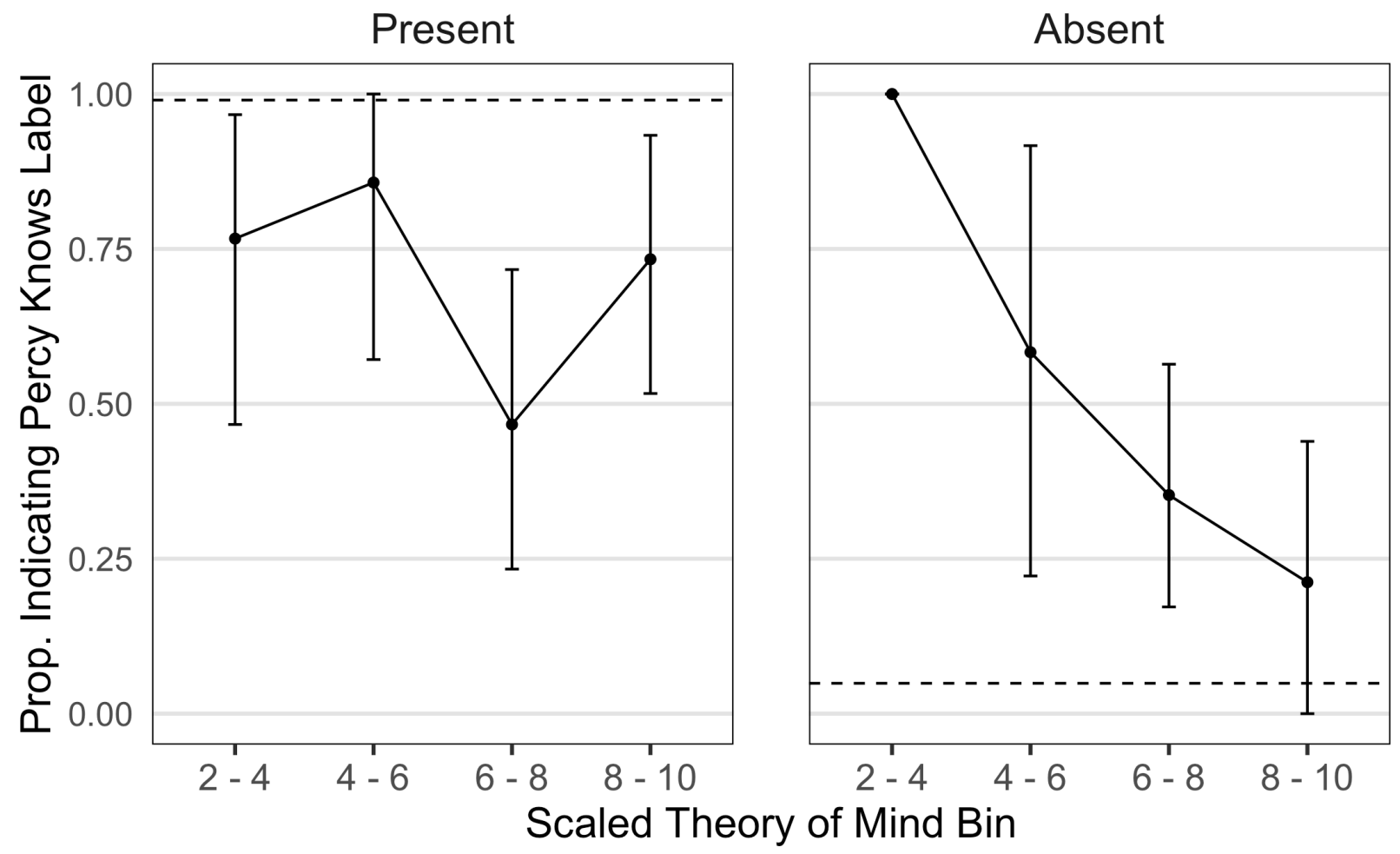

Figure 7. Relation between Theory of Mind score and assessments of Percy's knowledge in Experiment 3. The solid black line and dots indicate the proportion of trials in which children indicated that Percy "knows" the labeled object's name, as a function of Theory of Mind score. 
The dashed red line indicates the proportion of trials in which adults indicated that Percy "knows" the labeled object's name. Error bars show bootstrapped confidence intervals.

Finally, to directly evaluate whether the provision of pedagogical cues in Experiment 3 affected children's beliefs about Percy's knowledge of the object labels, we used a linear model to test whether children's beliefs about whether Percy shared their knowledge of the labeled object's name differed between Experiment 2, where the labels were coined, and Experiment 3, where the labels were taught. This model grouped together older and younger children from the two studies and predicted participants' judgment that Percy knew the labeled object's name as a function of Puppet Presence (Present vs. Absent), Experiment (Coined labels in Experiment 2 vs. Taught labels in Experiment 3), Age, Theory of Mind, the interaction between Theory of Mind and Puppet Presence, and the interaction between Puppet Presence and Experiment. Because this model did not find a significant interaction between Puppet Presence and Experiment $(B=0, \mathrm{CI}$ $=[-.27, .26], t(123)=.03, p=.97)$, we reverted to a model without this interaction term.

This analysis did not yield a significant effect of Experiment $(B=-.07, \mathrm{CI}=[-.20, .06]$, $t(124)=-1.09, p=.28)$, indicating that children's judgments of whether Percy knew the labels were not affected by whether the labels were introduced pedagogically (Experiment 3 ) or coined (Experiment 2). The model also did not find a significant effect of Age $(B=-.01, \mathrm{CI}=[-.01,0]$, $t(124)=-1.48, p=.14)$. Consistent with previous analyses, however, we found a significant effect of Puppet Presence $(B=-.30, C I=[-.43,-.17], t(124)=-4.50, p<.001)$, indicating that across Experiments 2 and 3, children were less likely to judge that Percy knew the labeled object's name when he was absent than present during the label's introduction. Finally, although Theory of Mind $(B=-.01, \mathrm{CI}=[-.05, .03], t(124)=-.58, p=.56)$ was not a significant predictor, 
the interaction between Theory of Mind and Puppet Presence was significant $(B=-.06$, CI [-.11, $-.01], t(124)=-2.52, p<.05)$, suggesting that, across Experiments 2 and 3, children with stronger theory of mind were less likely to indicate that Percy knew the object labels when Percy was absent when the labels had been introduced, compared to when he was present.

\section{Experiment 4}

Experiment 4 returns to a puzzle raised by Experiment 2. In that experiment, older children and adults who participated in coining a name for the labeled object ("What should we call it? Should we call it a dax or a zev?") while Percy was sleeping typically indicated that Percy did not know the name of this object, and then reliably chose the previously-unlabeled object as the referent of Percy's distinct label (“Can you give me the bem?"). Although these results suggest that participants' mutual exclusivity inferences must have been based on their own knowledge of the labeled object's name - rather than their belief that Percy knew this name -

they leave open why this occurred. Why didn't older preschoolers and adults think that Percy's label could have referred to the labeled object, given that the labeled object's name was made up and was thus unlikely to be the conventional name of that object?

A first possibility is that participants in Experiment 2 knew that the name of the labeled object was made up, but still designated it as the correct, conventional name of the object, either egocentrically, or perhaps because the experimenter agreed with their choice (e.g., "Okay, let's call it a dax!'). This could have led them to guess that Percy's distinct label (e.g., bem) must refer to the previously-unlabeled object, due to a belief that different object labels will refer to different kinds of objects (Clark, 1987, 2007; Markman, 1990, 1991).

A second possibility is that participants assumed that when the experimenter asked them to choose between two possible names for the labeled object, this was because the experimenter 
already knew which was the object's correct, conventional name, and was merely testing them. Thus, when the experimenter subsequently agreed with their choice of a name, participants may have assumed that they had selected the correct, conventional name for the labeled object. This could have then led participants to guess that Percy's distinct label must refer to the previouslyunlabeled object.

A third possibility is that, when the experimenter gave participants a choice of names for the labeled object, participants assumed that the experimenter was providing an exhaustive set of conventional names for the object, e.g., it can be called a dax or zev (Schulz \& Van Rooij, 2006), but nothing else. Thus, participants may have believed that the label they chose was not a coinage, but instead one of its two possible conventional names. This could have led them to guess that Percy's use of a third, distinct label (bem) must refer to the unlabeled object.

Finally, a fourth possibility is that by asking participants to choose a name for the labeled object, participants guessed that this object may not have a conventional name, but made no such inference about the unlabeled object, since they were not asked to select a name for it. Thus, when Percy requested an object using a label, participants could have reasoned that the unlabeled object was the best candidate, since it could have a name that Percy knows.

To distinguish among these alternatives, in Experiment 4 we asked participants to create a new name for the labeled object while Percy was sleeping (e.g., "What should we call it? Can you make up a name for it?"), and then agreed on this label (e.g., "Okay, let's call it a [participant's label]!"), instead of asking participants to select between two novel labels as we did in Experiment 2 (Figure 1). This method ruled out the possibility that participants' inferences could have been driven by their belief that the choice of names they were given for the labeled object comprised an exhaustive set of conventional names for that object, such that a distinct 
label must refer to the previously-unlabeled object. Also, the experimenter told participants that all objects had existing names, but that she did not know them, and to make sense of this, we introduced the objects as Percy's toys. This reduced the likelihood that participants might assume that the experimenter knows the name of the labeled object, blocking any inference that the experimenter's agreement with the participant's coinage implied that the participant had guessed the object's actual, conventional name. Additionally, indicating that all objects had existing names countered the possibility that participants might select the previously-unlabeled object on the assumption that only the object with the coined label lacked a conventional name (and that Percy, in using a label, must be referring to the previously-unlabeled object). Given these changes, we expected that if participants select the previously-unlabeled object in Experiment 4, this must be because they are willing to designate a label that they have created for an object as the conventional name of that object, even if other speakers do not know that name.

\section{Method}

Participants. Sixteen monolingual English-speaking children $(M=5.42$ years; range $=$ [4.55-6.00]; 8 females) participated, roughly matching the age of the "older" preschoolers tested in Experiment 2. Additionally, 17 English-speaking adults participated ( $M=21.18$ [18.50 -29.25]; 9 females). Three additional children were tested but were excluded from analyses, due to interruption of the study (1) or failing to create a novel name on three or more of the six trials (2; see below). Participants were recruited, tested, and compensated as before.

Materials and Procedure. All aspects of the word learning task were identical to the Puppet Absent condition of Experiment 2, with two exceptions. First, participants were asked to create a name for the labeled object, a task that they received training with at the beginning of 
the session. Second, the objects were introduced as Percy's toys, and the experimenter told participants that all of the objects have names, but that she did not know them.

At the beginning of the session, Percy came out of his house and interacted with the participant as before, but also said "If you want, you can play with my toys. See? Here are my toys" and then gave all of the objects to the experimenter, before going back into his house to sleep. As in the other experiments, the experimenter then knocked on Percy's door to get him to come out, after which he again excused himself and reminded the experimenter and participant that they "can play with my toys." The experimenter then directed the participant's attention to the objects and indicated that they have names, but that she didn't know them, and that they would be making up names for them: “Percy's toys look really fun. They have names, but I don't know what they are. Maybe we can make up some names for the toys together!"

Participants were then given practice creating new labels. The experimenter drew the participant's attention to a novel object (not shown during the test trials) and said "What would be a good name for it? Hmmm... let me try... how about a funny sound like dax? That's a good funny name! Now it's your turn. Can you make up a funny name?" The experimenter gave additional examples if the participant had difficulty thinking of new labels. Participants had to create at least two novel labels before proceeding to the test trials. If participants produced existing words (e.g., orange, ruler) they were prompted further.

Prior to each test trial, the experimenter reminded the participant that each of the presented objects had labels: "Look! These things have names but I don't know what they are." The experimenter invited the participant to create a label for the named object ("What should we call it? Can you make up a name for it?”; Figure 1), and ratified the participant's label (“Okay, let's call it a [participant's label]!"). Entirely novel word forms (e.g., foov) and novel compounds 
of existing words (e.g., cloudhammer) were accepted, but if participants produced a conventional word form (e.g., orange), they were prompted to come up with a new, "funny" name. Both adults and children typically produced acceptable coinages for the objects (an average of 5.47 out of 6 for adults, and 4.38 out of 6 for children). Participants that did not produce acceptable coinages on three or more of the six test trials were excluded $(n=2)$. We created an ordered list of novel words for Percy to use in his request on each trial (e.g., "Can you give me the [bem]?"; see Supplementary Material), and only selected novel words out of order when they would otherwise have overlapped in phonological onset with the participant's created label for that trial (e.g., bem and biff). All other aspects of the materials and procedure were the same as in Experiment 2.
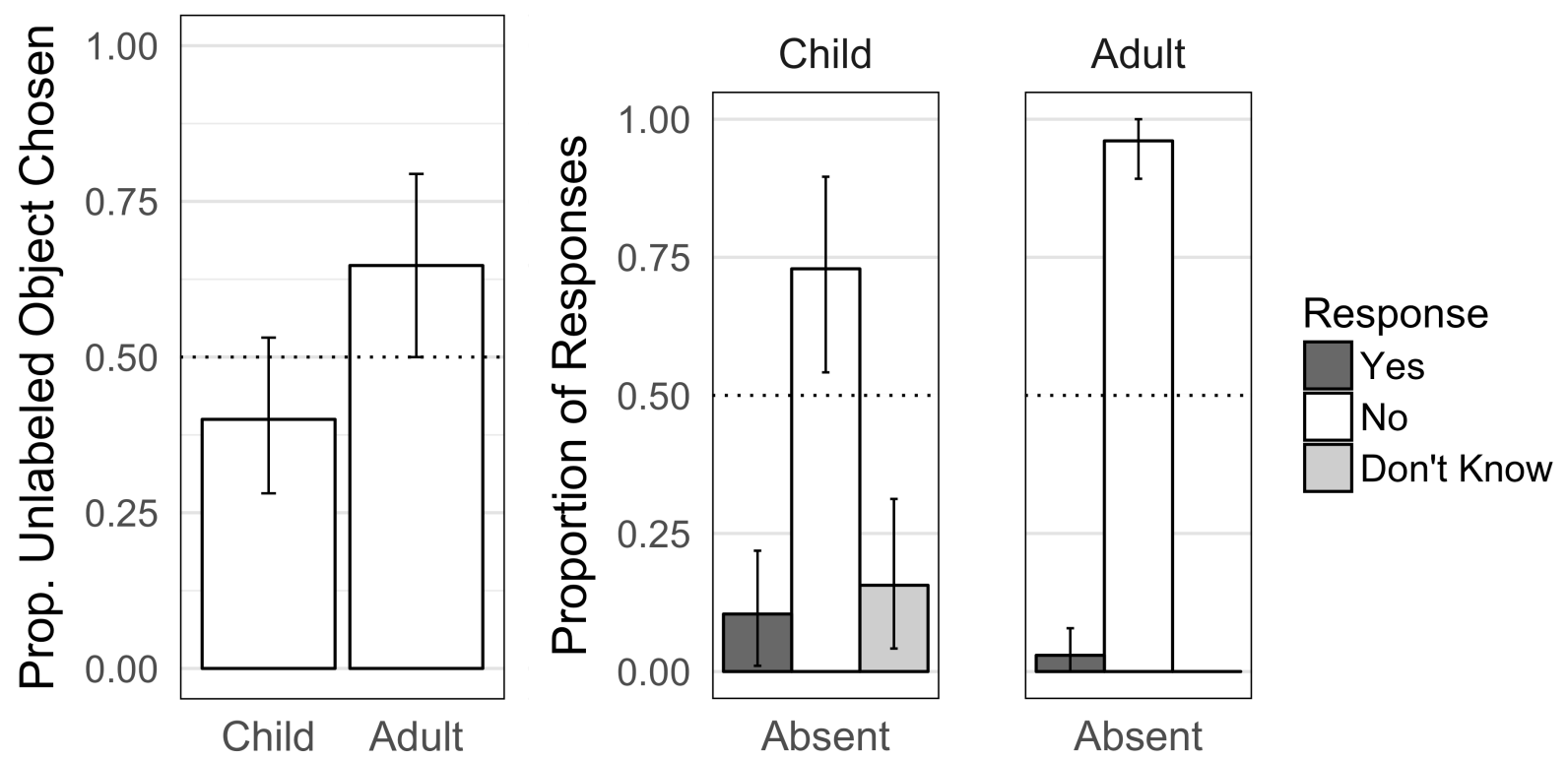

Figure 8. Data from Experiment 4. The proportion of trials in which children and adults selected the previously-unlabeled object (left panel) and the proportion of trials in which children and adults said that Percy knew the labeled object's name (right panel).

\section{Results}

We organize this section according to analyses of participants' (1) object choices, and (2) judgments of whether Percy knew the labeled object's name (Figure 8). 
Analyses of participants' object choices. In contrast to Experiment 2, children did not select the previously-unlabeled object reliably more often than chance $(M=.40[.29, .53])$, and there was only a non-significant trend for adults to select this object more than chance $(M=.65$ $[.50, .78], t(16)=2.02, p=.06$; Figure 8). Planned t-tests showed that both adults and children in Experiment 4 selected the previously-unlabeled object significantly less often than their counterparts in the Puppet Absent condition of Experiment 2, which Experiment 4 was modeled after (Adults from Experiment 2: $M=.90[.80, .97], t(25.68)=2.95, p<.01$; Older children from Experiment $2: M=.72[.57, .85], t(29.04)=3.18, p<.01)$.

These findings suggest that differences in the procedure of Experiment 2 (Puppet Absent condition) and Experiment 4, perhaps in the pragmatics of the task, led older children and adults to make mutual exclusivity inferences more often in Experiment 2 than in Experiment 4. One possibility is that when the experimenter gave participants in Experiment 2 a choice between two names for the labeled object (e.g., "Should we call it a dax or a zev?") — which we did not do in Experiment 4 - participants guessed that the experimenter was providing an exhaustive set of conventional labels for this object, leading them to later infer that Percy's use of a distinct label (e.g, bem) referred to the unlabeled object. Participants in Experiment 2 might also have assumed that the experimenter knew the labeled object's conventional name, leading them to infer that when the experimenter accepted their choice of a name, this meant that they had selected the correct, conventional name of the labeled object (such that another distinct label must refer to the unlabeled object); We countered this possibility in Experiment 4 by telling participants that the experimenter did not in fact know the objects' names. Finally, it is also possible that participants in Experiment 2 guessed that the labeled object — but not the unlabeled object — lacked a conventional name because the experimenter only asked participants to select a name for the 
labeled object, a possibility that we addressed in Experiment 4 by telling participants that all objects had names, but that the experimenter was ignorant of them.

Regardless of why participants made mutual exclusivity inferences in Experiment 2 but not in Experiment 4, our findings suggest that children and adults do not simply assume that a label that they have created for an object along with another person is the correct, conventional name of that object in their language. In contrast, children and adults may assume that a label that they have been taught for an object is the conventional name of that object, and this may help explain why participants made mutual exclusivity inferences in Experiments 1 and 3 when the labels were introduced pedagogically. We return to this issue in the General Discussion.

As before, we used a logistic regression to test whether children's Age, Theory of Mind, and beliefs that Percy shared their knowledge of the labeled object's name (Puppet Knowledge) predicted their choice of the unlabeled object in response to Percy's request. This analysis did not yield significant effects of Puppet Knowledge $\left(\mathrm{OR}=.11, \mathrm{CI}=[0, .98], \chi^{2}(1)=2.87, p=.09\right)$, Theory of Mind $\left(\mathrm{OR}=.92, \mathrm{CI}=[.61,1.32], \chi^{2}(1)=.21, p=.65\right)$, or Age $(\mathrm{OR}=.98, \mathrm{CI}=[.84$, $\left.1.15], \chi^{2}(1)=.11, p=.74\right)$. Thus, contrary to epistemic accounts, we again observed that children's theory of mind ability, and their belief that Percy knew the name for the labeled object, was not significantly related to their tendency to select the unlabeled object. ${ }^{3}$

Analyses of participants' judgments of Percy's knowledge. As in the Puppet Absent conditions of Experiments 2 and 3, children and adults rarely indicated that Percy knew the name of the labeled object (Children: $M=.10, \mathrm{CI}=[.01, .23]$; Adults: $M=.03[0, .07]$; Figure 8 ). We used a linear model to predict children's judgments of whether Percy knew the labeled object's name, from children's Theory of Mind and Age. We found a significant effect of Theory of Mind

\footnotetext{
${ }^{3}$ Because there was almost no variability in adults' judgments of whether Percy knew the labeled object's name (Figure 9, right panel), we only included a model for children.
} 
$(B=-.07, \mathrm{CI}=[-.13,-.01], t(12)=-2.37, p<.05)$, over and above Age $(B=0, \mathrm{CI}=[-.02, .03]$, $t(12)=.30, p=.77)$, which reflected that children with higher Theory of Mind scores were significantly less likely to indicate that Percy knew the names of the objects. Consistent with Experiments 2 and 3, this suggests that theory of mind may help children to recognize when a label they know may not be known by others, such as when it was created in others' absence.

\section{General Discussion}

The present studies explored whether mutual exclusivity inferences require children to reason about the words their interlocutors know, and thus could have chosen to but did not say. Across four studies, we documented that both children and adults make mutual exclusivity inferences even when they believe that their interlocutor does not share their knowledge of relevant, alternative words, suggesting that mutual exclusivity need not require epistemic reasoning. As we discuss below, our findings suggest instead that children's and adults' own knowledge of an object's label - together with their belief that this is the conventional label for the object in their language, and that this convention applies to their interlocutor - can be sufficient to support their mutual exclusivity inferences. Additionally, and contrary to the claims of previous studies that have used mutual exclusivity as a proxy of children's beliefs that others share their knowledge (Diesendruck \& Markson, 2001; Diesendruck, 2005; Diesendruck et al., 2010), we found that children — especially those with stronger theory of mind ability — do not simply assume that labels they know will be known by other speakers, but are instead more conservative about attributing their knowledge to others. Below, we review our findings and discuss their implications for the cognitive basis of mutual exclusivity, and for how children learn about the scope of shared conventional knowledge.

\section{Implications for the cognitive basis of mutual exclusivity}


Our findings are difficult to explain for epistemic accounts of mutual exclusivity (e.g., Diesendruck, 2012; Diesendruck \& Markson, 2001). By these accounts, participants should have only made mutual exclusivity inferences when they believed that their interlocutor shared their knowledge of relevant, alternative labels. Experiment 1 provided preliminary evidence against this prediction by showing that even when three- and four-year-olds selected a new name for a labeled object in Percy's absence — i.e., when Percy would be unlikely to know this label — they still interpreted Percy's subsequent use of a distinct label as referring to the previously unlabeled object. Building on this finding, Experiment 2 showed that when directly asked, older preschoolers and adults typically denied that Percy knew the name of the labeled object when it was coined in his absence, and yet still made mutual exclusivity inferences in response to his subsequent use of a distinct label. More generally, across Experiments 2 and 3, we found that older preschoolers and adults more often indicated that Percy knew the labeled object's name when it had been coined (Experiment 2) or taught (Experiment 3) in his presence than when he had been absent; indeed, they rarely indicated that Percy knew the labeled object's name when he had been absent. And yet, critically, this variation in beliefs about Percy's knowledge did not predict whether participants made mutual exclusivity inferences, which older preschoolers and adults typically did make. Relatedly, although we found that theory of mind ability predicted children's tendency to make mutual exclusivity inferences in Experiment 1, we failed to replicate this relationship in our other experiments. Together, these findings provide strong evidence that, for children and adults alike, mutual exclusivity inferences need not require epistemic reasoning.

Why did children and adults make mutual exclusivity inferences in our experiments without attributing knowledge of relevant, alternative labels to their interlocutor? We suggest that children and adults assumed that the name that they knew for the labeled object (e.g., dax) 
was the conventional label for this object in their language, generating a normative expectation about how the object should be referenced by other competent speakers of their language, including Percy (e.g., it should be called a dax). Thus, when Percy requested an object using a different label (“Can you give me the bem?"), participants may have inferred that Percy must not be asking for the labeled object and must instead want the previously-unlabeled object, based on their belief that different words will pick out different referents (Clark, 1987, 2007; Markman, 1990, 1991; Markman \& Wachtel, 1988). Critically, by this alternative account, mutual exclusivity inferences are contingent on expecting other speakers of one's language to reference objects by their conventional labels, but are not contingent on believing that other speakers of the language actually know these labels. For example, a child that has just learned the word "spoon" may not think that another speaker of their language knows this word, but could still believe that it would be odd for them to refer to a spoon using a different word, if they believe that "spoon" is the conventional label for spoons in their language.

Importantly, our proposal predicts that, although beliefs about whether an interlocutor shares knowledge of an object's label should not affect the tendency to make mutual exclusivity inferences (as we found, see above), beliefs about whether an object label is conventional should be more consequential. Consistent with this, we found that older preschoolers and adults in Experiment 4 - who were given reason to think that the name they had created for the labeled object was not conventional - did not reliably make mutual exclusivity inferences when Percy later requested an object using a distinct label. Participants in Experiment 4 may have inferred that their name for the labeled object was unconventional because they had created this name from scratch after being told that the object had another, existing name that the experimenter did not know. In contrast, in Experiments 1 through 3, the older preschoolers and adults may have 
believed that the names for the labeled objects that they used were conventional, explaining why they made mutual exclusivity inferences in these experiments. For example, participants in Experiment 3 and in the Pedagogical conditions of Experiment 1 were taught the names of the labeled objects ("This is a dax"), and were given no reason to think that these names might not be conventional. And participants in Experiment 2 and in the Coinage conditions of Experiment 1 - who were asked to choose a name for the labeled object - may have assumed that they were being presented with an exhaustive set of conventional names for the labeled object (e.g., "Should we call it a dax or a zev), leading them to infer that Percy's use of a distinct label (e.g, bem) must refer to the other, previously-unlabeled object.

Our proposal also makes sense of previous findings regarding the conditions in which children make mutual exclusivity inferences. Recall, for example, that Diesendruck and Markson (2001) found that when children are taught an idiosyncratic fact for one of two novel objects ("I got this for Christmas"), and Percy then asks for an object using a second, distinct fact ("Can you give me the one from Mexico?"), children only reliably select the previously-unreferenced object if Percy was present throughout the trial, and not if he had been absent when the first fact was introduced. In contrast, children assume that a pair of object labels will be mutually exclusive even when their interlocutor was absent when the first label was introduced (Experiments 1-3, Puppet Absent conditions; Diesendruck \& Markson, 2001), though they do not assume that labels will be mutually exclusive when their interlocutor is a monolingual speaker of another language (Diesendruck et al., 2010) or an incompetent speaker of their own language (Diesendruck, 2005). Based on the assumption that mutual exclusivity requires epistemic reasoning, these previous findings have been interpreted as showing that preschoolers understand when to expect others to share their linguistic and cultural knowledge (Diesendruck, 2012; 
Sabbagh \& Henderson, 2007); by this account, preschoolers expect other competent speakers of their language to share their knowledge of object labels and object functions (which are also treated as mutually exclusive; Diesendruck, Carmel \& Markson, 2010), but not idiosyncratic facts (Diesendruck \& Markson, 2001; Diesendruck, 2005), and do not expect speakers of other languages or ignorant speakers of their own language to share their knowledge of object labels (Diesendruck, 2005; Diesendruck et al., 2010). Critically, however, our findings suggest that these previous data are better explained by appealing to children's understanding of conventionality itself. For example, preschoolers may understand that object labels and functions are conventional, such that if they have learned the conventional label or function of one object, another member of their community would be unlikely to refer to that object using a different label or function. Further, children might understand that idiosyncratic facts (e.g., "I got this for Christmas") are not conventional and might also understand that conventions for how to label objects do not apply to speakers of other languages or to incompetent speakers of their own language, such that they do not make mutual exclusivity inferences in these cases. Thus, children's understanding of whether the knowledge they have acquired is likely to be conventional, and to whom such conventions apply, is sufficient to explain previous findings, without appealing to children's beliefs about shared knowledge.

Our account applies not only to studies that have used mutual exclusivity to index children's beliefs about shared knowledge, but also to studies that have employed simplified measures with younger children and infants (Buresh \& Woodward, 2007; Byers-Heinlein, Chen, \& Xu, 2014; Graham, Stock, \& Henderson, 2006; Henderson \& Scott, 2015; Henderson \& Graham, 2005; Henderson \& Woodward, 2012; Novack et al., 2014; Scott \& Henderson, 2013). In these latter studies, children typically learn a piece of information about one of two objects 
from a speaker, e.g., that the speaker prefers an object, or that the object is called "a mido." Then, either the same speaker or a different speaker asks the child for an object using the same piece of information — e.g., "Where is the mido?" or "Where is the one I want?" — and the child's choice of objects is observed (or for infants, expectations are monitored via eye gaze). These studies find that, while children expect different speakers of the same language to use object labels in the same way (e.g., such that mido will refer to the same object across speakers), they do not expect speakers of different languages to use labels in the same way, nor do they expect different individuals to prefer or desire the same objects. Note, however, that these findings do not show that children expect other speakers of their language to know the words that they know, a priori. Instead, these studies show only that when children observe a speaker of their language use a word, like mido, they expect the speaker's meaning to match their own meaning for the word. Thus, these findings can be explained by the account we have proposed, in which children expect speakers of their language to follow the same conventions for naming objects that they do (without treating preferences or desires as conventional).

Although we have argued that mutual exclusivity does not require reasoning about an interlocutor's mental states, some mutual exclusivity inferences are likely to rely on this sort of reasoning. For example, as noted above, Diesendruck and Markson (2001) showed that preschoolers will treat a pair of idiosyncratic facts as mutually exclusive when they arise in the same conversation with their interlocutor: e.g., if children learn a new fact for a first object (e.g., "I got this for Christmas") while Percy is present, they expect Percy's later request using a new, distinct fact (e.g., "Can you give me the one from Mexico") to refer to the previouslyunreferenced object. In this situation, mutual exclusivity may involve epistemic reasoning: because Percy was present when the fact associated with the first object was introduced ("I got 
this for Christmas"), children can reason that Percy should know this fact and thus that it would be uncooperative for him to ask for this object using a different fact (Diesendruck \& Markson, 2001). While this finding suggests that children are capable of using epistemic reasoning to make mutual exclusivity inferences, the present findings suggest that epistemic reasoning does not subserve mutual exclusivity as it applies to object labels.

This idea - that the ability to treat facts exclusively within a conversation involves a different underlying process than the ability to treat words exclusively - also fits with the results of other studies. For example, although two-year-olds will treat a pair of object labels exclusively, they do not do the same for idiosyncratic facts (Scofield \& Behrend, 2007), suggesting that separate mechanisms - with distinct developmental trajectories - are at play. Relatedly, children and adolescents with Autism Spectrum Disorder - who have weak epistemic reasoning and socio-pragmatic ability - show more robust mutual exclusivity for object labels than for facts, with exclusivity for object labels correlated with vocabulary size but not sociopragmatic skill, and exclusivity for facts correlated with socio-pragmatic skill but not vocabulary size (de Marchena, Eigsti, Worek, Ono, \& Snedeker, 2011; see also Preissler \& Carey, 200 ). Our findings converge with these previous studies in suggesting that the ability to treat object labels as mutually exclusive does not depend on the sort of epistemic reasoning that allows facts to be treated as mutually exclusive within a conversation with the same interlocutor. ${ }^{4}$

\footnotetext{
${ }^{4}$ Although it has been argued that the tendency to treat words as mutually exclusive reflects a domain-specific word learning constraint (e.g., a bias to assume that each object will have a single label; Markman, 1990, 1991), we are agnostic on this issue. While we have argued that mutual exclusivity does not require epistemic reasoning, our account can still be thought of as pragmatic in nature. For example, we have argued that mutual exclusivity inferences require children to reason about whether the words they have learned are conventions (e.g., to explain why children did not make mutual exclusivity inferences in Experiment 4), and whether their interlocutors as parties to those conventions (e.g., to explain why children don't make mutual
} 


\section{Implications for how children reason about the scope of shared, conventional knowledge}

We have argued that previous data using the mutual exclusivity paradigm that have been taken to show that children have sophisticated beliefs about the scope of shared conventional knowledge can instead be explained by an alternative account that is neutral with respect to whether children expect others to share their knowledge. To address the question of how children infer that their knowledge will be shared with others, we introduced a new, direct measure of whether children expect their interlocutor to share their knowledge, independent of mutual exclusivity. Specifically, in Experiments 2 through 4, we asked children whether Percy “...knows we call this a [dax]" after they selected an object's label (Experiment 2), were taught an object label (Experiment 3), or made one up from scratch (Experiment 4), while varying whether Percy was present or absent when the label was introduced. Our findings run counter to previous claims, and suggest that children can be quite conservative about attributing their knowledge to others. Additionally, our findings point to several factors that affect children's reasoning about whether others share their knowledge of object labels, which we review below.

To begin, in Experiments 2 through 4, we found that older preschoolers were relatively unlikely to indicate that Percy knew the labeled object's name when he had been absent, regardless of whether they had selected it (Experiment 2: 15\%), had been taught it (Experiment 3: 35\%), or had created it from scratch (Experiment 4: 10\%). This provides direct evidence against claims that children expect object labels that they know to be known by other competent

exclusivity inferences in response to speakers of other languages or incompetent speakers of their own language). Although these requirements are not typically incorporated into domainspecific accounts of mutual exclusivity, it is possible that they could be (see de Marchena et al., 2011 for discussion). 
speakers of their language (Diesendruck \& Markson, 2001; Diesendruck, 2005; Diesendruck et al., 2010). Older preschoolers' tendency to deny that Percy shared their knowledge of the labels was in fact a developmentally mature response, as adults also rarely judged that Percy shared their knowledge across our experiments when Percy had been absent (Experiment 2: 0\%, Experiment 3: 5\%, Experiment 4: 3\%). Both older preschoolers and adults, in contrast, were more likely to indicate that Percy knew the labeled object's name when he had been present when the label was introduced and had himself used the label, e.g., "Oh, so that's a dax" (Experiment 2: Older children: 54\%, Adults: 94\%; Experiment 3: Older children: 71\%, Adults: 99\%). Thus, by the late preschool years, children can infer that a label that they have been introduced to in another person's presence, and that they have directly observed them use, is likely to be known by that person.

Beyond directly observing a speaker use a word, how might children infer whether that speaker knows the words that they know? One possible cue to shared knowledge that we considered was whether the labels were introduced to children pedagogically, as opposed to with uncertainty. Here, we were motivated by previous findings that pedagogical cues lead children to assume that knowledge is shared and generalizable (Csibra \& Gergely, 2009), as well as studies showing that parents are more likely to introduce conventional labels that they know to children using ostensive cues (e.g., "This is a __"), and are more likely to indicate their uncertainty when referring to objects for which they do not know conventional labels, either explicitly (e.g., "I don't know what this is") or more implicitly (e.g., "You think it's a bike?" with rising intonation in reference to an unknown object; Henderson \& Sabbagh, 2010).

Experiments 2 and 3 provided a test of whether children use information about whether a new label has been introduced with uncertainty (Experiment 2; e.g., "I don't know what these 
things are... Should we call it a dax or a zev?") or pedagogically (Experiment 3; e.g., "Look at this one... This is a dax") to make inferences about whether that label will be known by another speaker. Interestingly, we found that the provision of pedagogical cues made little difference, as children in Experiment 3 were no more likely to say that Percy knew the labeled object's name than children in Experiment 2, regardless of whether Percy was present or absent when the label was introduced. Thus, our findings suggest that simply teaching children a label does not lead them to assume that other speakers of their language will know that label.

Interestingly, we found that one of the strongest predictors of children's beliefs about whether Percy shared their knowledge of the object labels was their theory of mind ability. Specifically, although we did not detect a significant relation between children's performance on the theory of mind battery and their tendency to make mutual exclusivity inferences in Experiments 2 through 4, we found that children with weaker theory of mind ability were more likely to say that Percy knew the name of the labeled object than children with stronger theory of mind, especially when Percy had been absent when this label was introduced. These effects held over and above children's age. These findings suggest that children with weak theory of mind ability may initially fail to consider that others may not share their knowledge of object labels, while children with stronger theory of mind are relatively conservative about attributing knowledge to others (see Taylor, Cartwright \& Bowden, 1991, for related evidence on children's naïve realism). To our knowledge, these findings are the first to directly relate children's beliefs about shared linguistic knowledge to their developing theory of mind ability.

One possibility that our data open is that young children's weaker theory of mind ability may initially provide an advantage for communicative development, by allowing children to assume that the words that they know can be used with others (Sabbagh \& Henderson, 2007). 
This could in effect allow communication to get "off the ground", because children's assumption that they will be understood will often be valid. The drawback of this assumption, of course, is that children would sometimes misattribute knowledge of words that they know to others, and would ultimately have to scale back from such over-extensions to avoid communicative failures. Indeed, children appear to face a difficult learning problem in guessing whether the words they know will be known by others, because words can vary intricately in how widely they are shared within a language community, just like other social conventions (Lewis, 1969). This point which has rarely been acknowledged in the literature on how children learn linguistic conventions — is articulated clearly by the psychologist Herbert Clark (1998, p. 63):

...Suppose I tell you, 'You've got a sclerotic aorta, which could well cause a myocardial infarction.' Sclerotic, aorta, myocardial and infarction are perfectly good English words, but how can I be sure you know them? Or I tell you, 'The Broncos were in a nickel defense, but the linebackers still weren't able to cover the deep outside routes': Nickel, linebacker, and outside routes are also fine English expressions, but how can I be confident you share them? ... You and I each have a personal lexicon, a stock of words we know to varying degrees, and even though we both speak English, our personal lexicons differ. The differences may be enormous.

Clark's observation suggests that not all speakers of a particular language know — or should even be expected to know — the same word meanings. Shared linguistic knowledge does not break down along grammatical lines, e.g., such that common nouns are known by other speakers but not proper nouns, but might instead be a function of the communities that speakers belong to. For instance, as Clark suggests, football aficionados may share knowledge of a specialized sense of "nickel" and doctors may share knowledge of words like "infarction" that other English speakers do not know. From this perspective, it makes sense that adults and children with stronger theory of mind ability typically denied that Percy knew the name of a novel object that they were taught while Percy was sleeping (Experiment 3, Puppet Absent 
condition). Given that they had never seen this object before, participants could have reasoned that Percy was unlikely to have encountered this object and learned its name.

While children with weaker theory of mind may initially learn and use words without regard for whether others know those words, developing such expectations may be an important component of language acquisition. Mature speakers of a language often design their utterances guided by their knowledge of what words their addressees are likely to know (e.g., whether they know words like "infarction" or the specialized sense of "nickel"; Clark, 1998), and listeners can make socio-pragmatic inferences based on their expectations of what word meanings they share with their interlocutors. Thus, an important task for future research will be to characterize how children develop a nuanced understanding of when their interlocutors are likely to share their linguistic knowledge. Future research should also develop more sensitive methods for measuring children's beliefs about shared knowledge, to go beyond the simple explicit measure employed in our studies.

Finally, another open question left open by our data is how children learn whether a piece of knowledge is conventional in the first place (e.g., that a particular label is the word that speakers of a language use to denote a particular meaning). Based on the findings of Experiment 4, we have argued that children understand that a label that they have created for an object is unlikely to be the correct, conventional name of that object in their language. However, outside of these unusual circumstances, preschoolers appear to assume that object labels are conventional, an assumption that they do not extend to other knowledge that they acquire, such as idiosyncratic facts about objects. An important goal for future research will be to explore how children develop assumptions regarding conventionality, and what cognitive abilities this requires. 


\section{Acknowledgments}

We thank Sara Al Mughairy, Elizabeth Kaplan, Catherine Berner, Katie Kimura, Karen Bejar, Reni Forer, Sarina Gross, Laura Kelly, Alagia Cirolia, Becca Berelson, Michellie McDonald-Bryan, Jordan Wong, Antonia Langenhoff, Dorota Swierzewicz, Nicholas Davis and Lara Yedikian for assistance with data collection. We also thank Ariel Starr and Catherine Berner for feedback on an earlier version of this manuscript. We are grateful to the Bay Area Discovery Museum in Sausalito, the Lawrence Hall of Science and Habitot Children's Museum in Berkeley, and the families of children in the Berkeley and San Diego areas for participating in our studies. This research was supported by an award from the National Science Foundation (SBE-16302040) to MS, an NSF graduate research fellowship to RF, and an award from the

James S. McDonnell Foundation to DB. 


\section{References}

Baldwin, D. A. (1993). Early referential understanding: Infants' ability to recognize referential acts for what they are. Developmental Psychology, 29(5), 832-843. http://doi.org/10.1037/0012-1649.29.5.832

Bloom, P. (2000). How children learn the meanings of words. Cambridge, MA: MIT Press.

Bloom, P., \& Markson, L. (1998). Capacities underlying word learning. Trends in Cognitive Sciences, 2(2), 67-73. http://doi.org/10.1016/S1364-6613(98)01121-8

Bloom, P., \& Markson, L. (2001). Are there principles that apply only to the acquisition of words? A reply to Waxman and Booth. Cognition, 78(1), 89-90. http://doi.org/10.1016/S0010-0277(00)00111-6

Booth, A. E., \& Waxman, S. R. (2002). Word learning is 'smart': evidence that conceptual information affects preschoolers' extension of novel words. Cognition, 84(1), B11-B22. http://doi.org/10.1016/S0010-0277(02)00015-X

Buresh, J. S., \& Woodward, A. L. (2007). Infants track action goals within and across agents. Cognition, 104(2), 287-314. http://doi.org/10.1016/j.cognition.2006.07.001

Byers-Heinlein, K., Chen, K. H., \& Xu, F. (2014). Surmounting the Tower of Babel: Monolingual and bilingual 2-year-olds' understanding of the nature of foreign language words. Journal of Experimental Child Psychology, 119, 87-100. http://doi.org/10.1016/j.jecp.2013.09.011

Casler, K., \& Kelemen, D. (2005). Young children's rapid learning about artifacts. Developmental Science.

Clark, E. (1987). The principle of contrast: A constraint on language acquisition. In B. 
MacWhinney (Ed.), Mechanisms of Language Acquisition. Hillsdale, NJ: Erlbaum

Clark, H. H. (1998). Communal lexicons. In K. Malmkjaer \& J. Williams (Eds.), Context in language learning and language understanding (pp. 63-87). Ernst Klett Sprachen.

Clark, E. V. (2007). Conventionality and contrast in language acquisition. In M. Sabbagh \& C. Kalish (Eds.), New directions in child \& adolescent development: No. 115. Right thinking: The development of conventionality (pp. 11-23). http://doi.org/10.1002/cad

Csibra, G., \& Gergely, G. (2009). Natural pedagogy. Trends in Cognitive Sciences, 13(4), 148153. http://doi.org/10.1016/J.TICS.2009.01.005

de Marchena, A., Eigsti, I. M., Worek, A., Ono, K. E., \& Snedeker, J. (2011). Mutual exclusivity in autism spectrum disorders: Testing the pragmatic hypothesis. Cognition, 119(1), 96-113. http://doi.org/10.1016/j.cognition.2010.12.011

Diesendruck, G. (2005). The principles of conventionality and contrast in word learning: an empirical examination. Developmental Psychology, 41(3), 451-463. http://doi.org/10.1037/0012-1649.41.3.451

Diesendruck, G. (2012). The scope and origins of children's assumption of conventionality. In Access to language and cognitive development (pp. 116-134). Oxford: Oxford University Press. http://doi.org/10.1093/acprof:oso/9780199592722.003.0007

Diesendruck, G., Carmel, N., \& Markson, L. (2010). Children's sensitivity to the conventionality of sources. Child Development, 81(2), 652-668. http://doi.org/10.1111/j.14678624.2009.01421.x

Diesendruck, G., \& Markson, L. (2001). Children's avoidance of lexical overlap: a pragmatic account. Developmental Psychology, 37(5), 630-641. 
Diesendruck, G., \& Markson, L. (2011). Children's assumption of the conventionality of culture. Child Development Perspectives, 5(3), 189-195. http://doi.org/10.1111/j.17508606.2010.00156.x

Frank, M. C., Goodman, N. D., \& Tenenbaum, J. B. (2009). Using speakers' referential intentions to model early cross-situational word learning. Psychological Science, 20(5), 578-585. http://doi.org/10.1111/j.1467-9280.2009.02335.x

Golinkoff, R. M., Hirsh-Pasek, K., Bailey, L. M., \& Wenger, N. R. (1992). Young children and adults use lexical principles to learn new nouns. Developmental Psychology, 28(1), 99-108. http://doi.org/10.1037/0012-1649.28.1.99

Graham, S. A., Poulin-Dubois, D., \& Baker, R. K. (1998). Infants' disambiguation of novel object words. First Language, 18(53), 149-164. http://doi.org/10.1177/014272379801805302

Graham, S. A., Stock, H., \& Henderson, A. M. E. (2006). Nineteen-month-olds ' understanding of the conventionality of object labels versus desires. Infancy, 9(3), 341-351.

Grice, H. P. (1975). Logic and conversastion. In P. Cole \& J. L. Morgan (Eds.), Syntax and semantics. Volume 3: Speech acts (pp. 225-242). New York: Seminar Press.

Halberda, J. (2006). Is this a dax which I see before me? Use of the logical argument disjunctive syllogism supports word-learning in children and adults. Cognitive Psychology, 53(4), 310344. http://doi.org/10.1016/J.COGPSYCH.2006.04.003

Henderson, A. M. E., \& Sabbagh, M. A. (2010). Parents' use of conventional and unconventional labels in conversations with their preschoolers. Journal of Child Language, 37(4), 793-816. http://doi.org/10.1017/S0305000909990122 
Henderson, A. M. E., \& Scott, J. C. (2015). She called that thing a mido, but should you call it a mido too? Linguistic experience influences infants' expectations of conventionality. Frontiers in Psychology, 6(332), 1-11. http://doi.org/10.3389/fpsyg.2015.00332

Henderson, A. M., \& Graham, S. A. (2005). Two-year-olds' appreciation of the shared nature of object labels. Journal of Cognition and Development, 6(3), 307-323. http://doi.org/10.1207/s15327647jcd0603

Henderson, A. M., \& Woodward, A. (2012). Nine-month-old infants generalize object labels, but not object preferences across individuals. Developmental Science, 15(5), 641-52. http://doi.org/10.1111/j.1467-7687.2012.01157.x

Kalish, C. W., \& Sabbagh, M. A. (2007). Conventionality and cognitive Development: Learning to think the right way. In M. Sabbagh \& C. Kalish (Eds.), New directions in child \& adolescent development: No. 115. Right thinking: The development of conventionality (pp. 1-9). http://doi.org/10.1002/cad

Koenig, M. A., \& Harris, P. L. (2005). Preschoolers mistrust ignorant and inaccurate speakers. Child Development, 76(6), 1261-1277. http://doi.org/10.1111/j.1467-8624.2005.00849.x

Lewis, D. (1969). Convention: A Philosophical Study. Cambridge, MA: Harvard University Press.

Markman, E. (1990). Constraints children place on word meanings. Cognitive Science, 14(1), 55-77. http://doi.org/10.1016/0364-0213(90)90026-S

Markman, E. (1991). Categorization and naming in children: Problems of induction. Cambridge: MIT Press.

Markman, E. M., Wasow, J. L., \& Hansen, M. B. (2003). Use of the mutual exclusivity 
assumption by young word learners. Cognitive Psychology, 47(3), 241-275.

http://doi.org/10.1016/S0010-0285(03)00034-3

Markman, E., \& Wachtel, G. (1988). Children's use of mutual exclusivity to constrain the meanings of words. Cognitive Psychology, 20(2), 121-157.

Merriman, W., \& Bowman, L. (1989). The mutual exclusivity bias in children's word learning. Monographs of the Society for Research in Child Development, i-129.

Novack, M. A., Henderson, A. M. E., Woodward, A. L., Novack, M. A., Henderson, A. M. E., \& Woodward, A. L. (2014). Twelve-month-old infants generalize novel signed labels, but not preferences across individuals. Journal of Cognition and Development, 15(4), 539-550. http://doi.org/10.1080/15248372.2013.782460

Preissler, M. A., \& Carey, S. (2005). The role of inferences about referential intent in word learning: Evidence from autism. Cognition, 97(1), 13-23. http://doi.org/10.1016/j.cognition.2005.01.008

Rakoczy, H., \& Schmidt, M. F. H. (2013). The early ontogeny of social norms, 7(1), 17-21. http://doi.org/10.1111/cdep.12010

Sabbagh, M. A., \& Baldwin, D. A. (2001). Learning words from knowledgeable versus ignorant speakers: Links between preschoolers' theory of mind and semantic development. Child Development, 72(4), 1054-1070. http://doi.org/10.1111/1467-8624.00334

Sabbagh, M. A., \& Henderson, A. M. E. (2007). How an appreciation of conventionality shapes early word learning. In M. Sabbagh \& C. Kalish (Eds.), New directions in child \& adolescent development: No. 115. Right thinking: The development of conventionality (pp. 25-38). http://doi.org/10.1002/cad 
Sabbagh, M. A., Wdowiak, S. D., \& Ottaway, J. M. (2003). Do word learners ignore ignorant speakers? Journal of Child Language, 30(4), S0305000903005828. http://doi.org/10.1017/S0305000903005828

Schulz, K., \& Van Rooij, R. (2006). Pragmatic meaning and non-monotonic reasoning: The case of exhaustive interpretation. Linguistics and Philosophy, 29(2), 205-250. http://doi.org/10.1007/s10988-005-3760-4

Scofield, J., \& Behrend, D. a. (2007). Two-year-olds differentially disambiguate novel words and facts. Journal of Child Language, 34(4), 875-889. http://doi.org/10.1017/S0305000907008100

Scott, J. C., \& Henderson, A. M. E. (2013). Language matters: Thirteen-month-olds understand that the language a speaker uses constrains conventionality. Developmental Psychology, 49(11), 2102-11. http://doi.org/10.1037/a0031981

Smith, L., Jones, S., \& Landau, B. (1996). Naming in young children: A dumb attentional mechanism? Cognition, 60(2), 143-171.

[dataset] Srinivasan, M., Foushee, R., Bartnof, A., \& Barner, D. (2018, August 29). Linguistic conventionality and the role of epistemic reasoning in children's mutual exclusivity inferences. Retrieved from osf.io/chmjt

Taylor, M., Cartwright, B. S., \& Bowden, T. (1991). Perspective taking and theory of mind: Do children predict interpretive diversity as a function of differences in observers' knowledge?. Child Development, 62(6), 1334-1351.

Tomasello, M. (2003). Constructing a language: A usage-based approach to child language acquisition. Cambridge: Harvard University Press. 
Waxman, S. R., \& Booth, A. E. (2000). Principles that are invoked in the acquisition of words, but not facts. Cognition, 77(2). http://doi.org/10.1016/S0010-0277(00)00103-7

Xu, F., Cote, M., \& Baker, A. (2005). Labeling guides object individuation in 12-Month-Old Infants. Psychological Science, 16(5), 372-377. http://doi.org/10.1111/j.09567976.2005.01543.x 